\title{
HIV-1 Tropism Determination Using a Phenotypic Env Recombinant Viral Assay Highlights Overestimation of CXCR4-Usage by Genotypic Prediction Algorithms for CRRF01_AE and CRF02_AG
}

\author{
Martin Mulinge ${ }^{1}$, Morgane Lemaire ${ }^{1}$, Jean-Yves Servais ${ }^{1}$, Arkadiusz Rybicki ${ }^{1}$, Daniel Struck ${ }^{1}$, \\ Eveline Santos da Silva', Chris Verhofstede ${ }^{3}$, Yolanda Lie ${ }^{4}$, Carole Seguin-Devaux ${ }^{1}$, Jean- \\ Claude Schmit ${ }^{1,2}$, Danielle Perez Bercoff ${ }^{1 *}$
}

1 Laboratory of Retrovirology, Centre Recherche Public de la Santé, Luxembourg, Luxembourg, 2 Service National des Maladies Infectieuses, Centre Hospitalier de Luxembourg, Luxembourg, Luxembourg, 3 AIDS Reference Laboratory, Ghent University, Ghent, Belgium, 4 Monogram Biosciences Inc., South San Francisco, California, United States of America

\begin{abstract}
Background: Human Immunodeficiency virus type-1 (HIV) entry into target cells involves binding of the viral envelope (Env) to CD4 and a coreceptor, mainly CCR5 or CXCR4. The only currently licensed HIV entry inhibitor, maraviroc, targets CCR5, and the presence of CXCX4-using strains must be excluded prior to treatment. Co-receptor usage can be assessed by phenotypic assays or through genotypic prediction. Here we compared the performance of a phenotypic Env-Recombinant Viral Assay (RVA) to the two most widely used genotypic prediction algorithms, Geno2Pheno ${ }_{\text {[coreceptor] }}$ and webPSSM.

Methods: Co-receptor tropism of samples from 73 subtype B and 219 non-B infections was measured phenotypically using a luciferase-tagged, NL4-3-based, RVA targeting Env. In parallel, tropism was inferred genotypically from the corresponding V3-loop sequences using Geno2Pheno [coreceptor] $(5-20 \%$ FPR) and webPSSM-R5X4. For discordant samples, phenotypic outcome was retested using co-receptor antagonists or the validated Trofile ${ }^{\circledR}$ Enhanced-Sensitivity-Tropism-Assay.

Results: The lower detection limit of the RVA was $2.5 \%$ and $5 \%$ for X4 and R5 minority variants respectively. A phenotype/ genotype result was obtained for 210 samples. Overall, concordance of phenotypic results with Geno2Pheno [coreceptor] was $85.2 \%$ and concordance with webPSSM was $79.5 \%$. For subtype B, concordance with Geno2pheno [coreceptor] was $94.4 \%$ and concordance with webPSSM was $79.6 \%$. High concordance of genotypic tools with phenotypic outcome was seen for subtype C (90\% for both tools). Main discordances involved CRF01_AE and CRF02_AG for both algorithms (CRF01_AE: 35.9\% discordances with Geno2Pheno ${ }_{\text {[coreceptor] }}$ and 28.2\% with webPSSM; CRF02_AG: 20.7\% for both algorithms). Genotypic prediction overestimated CXCR4-usage for both CRFs. For webPSSM, 40\% discordance was observed for subtype A.

Conclusions: Phenotypic assays remain the most accurate for most non-B subtypes and new subtype-specific rules should be developed for non-B subtypes, as research studies more and more draw conclusions from genotypically-inferred tropism, and to avoid unnecessarily precluding patients with limited treatment options from receiving maraviroc or other entry inhibitors.
\end{abstract}

Citation: Mulinge M, Lemaire M, Servais J-Y, Rybicki A, Struck D, et al. (2013) HIV-1 Tropism Determination Using a Phenotypic Env Recombinant Viral Assay Highlights Overestimation of CXCR4-Usage by Genotypic Prediction Algorithms for CRRF01_AE and CRF02_AG. PLoS ONE 8(5): e60566. doi:10.1371/ journal.pone.0060566

Editor: Zhiwei Chen, The University of Hong Kong, Hong Kong

Received November 23, 2012; Accepted February 28, 2013; Published May 8, 2013

Copyright: (c) 2013 Mulinge et al. This is an open-access article distributed under the terms of the Creative Commons Attribution License, which permits unrestricted use, distribution, and reproduction in any medium, provided the original author and source are credited.

Funding: This work was supported by the Luxembourg Ministry of Research and Education Grant \#MCESR LRTV20081003. MM and ESS were supported by PhD scholarships from the Fonds National de la Recherche (\# AFR grant PHD08-074 and AFR grant PHD-09-115, respectively). The funders had no role in study design, data collection and analysis, decision to publish, or preparation of the manuscript.

Competing Interests: One of the authors, Yolanda Lie, is an employee of a commercial company, Monogram Bioscience. There are no patents, products in development or marketed products to declare. This does not alter the authors' adherence to all the PLOS ONE policies on sharing data and materials, as detailed online in the guide for authors.

* E-mail: danielle.perezbercoff@crp-sante.lu

\section{Introduction}

Entry of the Human Immunodeficiency Virus type 1 (HIV-1) into target cells is a three-step process involving sequential interactions between the viral envelope glycoprotein trimer (Env) with the GD4 receptor and one of two coreceptors, CGR5 or
CXCR4 [1-7]. Binding to the CD4 receptor induces a series of conformational changes within Env that expose the third hypervariable region (V3-loop), which in turn binds the coreceptor, ultimately leading to the so-called "fusion-active" state required for fusion of the viral and cellular membranes [8]. The V3-loop, which is the main determinant of coreceptor binding, 
therefore largely accounts for viral tropism $[9,10]$, and viral strains are classified as R5, when using the CGR5 coreceptor for viral entry, X4 when using CXCR4, and dual-tropic or mixed (R5X4) when using both coreceptors [11]. Other regions of Env, and namely the $\mathrm{V} 1 / \mathrm{V} 2$ loops and the constant region $\mathrm{C} 4$, have been shown to also participate in viral tropism $[12,13]$.

R5 strains are generally predominant during the early stages of infection and are thought to be preferentially transmitted by distinct, not yet fully elucidated processes $[14,15]$. As infection progresses, viral strains feature increased variability within the infected host, and particularly, Envs acquire broadened coreceptor usage. At late stages of infection, X4 strains become dominant in $50 \%$ of patients infected with subtype B strains [16], but subtyperelated specificities have been reported [17-20]. X4 strains replicate more rapidly than $\mathrm{R} 5$ strains in vitro and have been associated with increased cytopathicity. In vivo, the appearance of $\mathrm{X} 4$ strains correlates with a sharp decline of $\mathrm{CD} 4^{+} \mathrm{T}$ cells and the onset of AIDS defining symptoms [21].

With the advent of entry inhibitors targeting CCR5, such as maraviroc, monitoring coreceptor usage has become prerequisite to the prescription of such entry inhibitors, in order to exclude the presence of $\mathrm{X} 4$ or $\mathrm{R} 5 / \mathrm{X} 4$ variants [22-24]. Under maraviroc selective pressure, pre-existing X4 or DM strains can be selected. CGR5 is a cellular target and resistance to maraviroc most often arises through the re-emergence of archived minority $\mathrm{X} 4$ strains rather than through a coreceptor usage switch or through the acquisition of mutations that allow gp120 to engage with drugbound CCR5 [25-28]. Viral coreceptor usage can be measured in vitro by phenotypic and genotypic assays [29]. Various phenotypic assays based on different techniques are currently available, including the Trofile ${ }^{\circledR}$ Enhanced-Sensitivity-TrofileAssay (ESTA) (Monogram Biosciences, South San Francisco, CA) [30], the Virco phenotypic test (Virco BVBA, Mechelen, Belgium) and others [30-33], which are based on pseudovirions, and assays based on recombinant viruses, among which are the Phenoscript test (VIRalliance, France) [34] and the Toulouse Tropism Test [35]. These assays, their design and performance are summarized in Table 1 . The Trofile assay is the most widely used in the clinic. It features a high sensitivity in detecting X4 minority variants [30]. Nonetheless, because phenotypic tests are expensive, time consuming and require specialized laboratories, more interest has been driven toward genotypic testing. Genotypic assays are based on predictions of coreceptor usage from the V3loop sequence using bioinformatic tools and algorithms. They are currently preferred in Europe due to their accessibility, rapid turnaround and low cost $[36,37]$. Many prediction tools are available, with similar specificities and sensitivities despite the fact that they are based on different algorithms involving the $11 / 25$ rule, the number of positively charged AA, the overall net charge of the V3 loop, or combinations thereof. Among them, Geno2Pheno ${ }_{[\text {cor- }}$ eceptor] [38] and webPSSM [39] are the most widely used. European Guidelines for HIV patient management currently recommend the use of Geno2Pheno ${ }_{[\text {coreceptor] }}$ with a $10 \%$ false positive rate (FPR) cut-off, which has been shown to provide the best balance between specificity and sensitivity for predicting R5 or X4/R5X4 tropism [40-43]. The major caveat of such algorithms however lies in the fact that they are based on V3loop sequences from subtypes B and C mainly, and inadequacies requiring fine-tuning or subtype-specific rules have been reported $[19,44-46]$.

This study evaluates the performance of an in-house Env recombinant viral assay (Env-RVA) targeting the full HIV Env ectodomain, in comparison to Geno2Pheno ${ }_{[\text {coreceptor] }}$ and webPSSM (Fig. 1). Concordance between the RVA and
Geno2Pheno $0_{\text {[coreceptor] }}$ with a false positive cutoff set at $10 \%$ was $85.2 \%$ and concordance with webPSSM was $79.6 \%$. Discordant results most often involved non-B subtypes, particularly subtype A1 for webPSSM and CRF01_AE and CRF02_AG for both algorithms. Repeat experiments in the presence of coreceptor antagonists and, when possible, testing the sample using the Trofile ESTA, confirmed phenotypic results of the RVA. Taken together, these results highlight that prediction algorithms are not always accurate for predicting tropism of some subtypes, particularly CRF01_AE and CRF02_AG and underscore the usefulness of maintaining phenotypic testing as well as to adapt algorithms for certain subtypes and recombinant forms.

\section{Materials and Methods}

\section{Study Population}

Plasma samples from 292 patients infected with HIV-1 subtypes B (73), Al (17), C (21), D (15), F (15), G (55), CRF01_AE (42) and CRF02_AG (54) were included in the study. Left-over plasma obtained from samples for routine clinical tests was used. Ethical approval for use of left-over plasma was obtained from the Comité National d'Ethique pour la Recherche in Luxembourg for HIV assay validation in Luxembourg for HIV assay validation without patient informed consent. The IRB waived the need for written informed consent from the participants for this study. HIV-1 subtypes were determined from HIV-1 PR-RT and Env sequences spanning the V3-loop using COMET (www.comet.retrovirology. lu) and the REGA HIV subtyping tool [47]. CD4 counts ranged from 11 cells $/ \mathrm{mm}^{3}$ to 1460 cells $/ \mathrm{mm}^{3}$ (mean: 391 and median: 356 cells $/ \mathrm{mm}^{3}$ ). Plasma viral load (VL) (Abbott m2000 RealTime HIV-1 assay) ranged from 466 to $1,350,000 \mathrm{RNA}$ copies/ml for all subtypes, with a mean and median of 14,055 and 71,115 RNA copies/ml respectively. 26/73 subtype $\mathrm{B}$ samples with $\mathrm{VL}<10^{3}$ RNA copies $/ \mathrm{mL}$ were also included to assess the RVA's performance for $\mathrm{VL}<10^{3} \mathrm{RNA}$ copies $/ \mathrm{ml}$.

\section{Cell Culture}

HEK293T cells were obtained from ATCC and were maintained in DMEM medium supplemented with 10\% Fetal Bovine Serum, $1 \%$ Glutamate, $50 \mu \mathrm{g} / \mathrm{ml}$ Penicillin and $50 \mu \mathrm{g} / \mathrm{ml}$ Streptomycin. U87.CD4.CCR5 and U87.CD4.CXCR4 cells were obtained from the NIH AIDS Reagent Program and were maintained in DMEM containing 10\% Fetal Bovine Serum, 1\% Glutamate, $300 \mu \mathrm{g} / \mathrm{ml}$ Geneticin and $1 \mu \mathrm{g} / \mathrm{ml}$ Puromycin to maintain CD4 and co-receptor expression respectively. All media supplements and antibiotics were sourced from Invitrogen, Belgium.

\section{Env Amplification}

One $\mathrm{ml}$ of plasma or of Env-recombinant virus supernatant was centrifuged at $24,000 \times \mathrm{g}$ for 1 hour at $4^{\circ} \mathrm{C}$ and viral RNA was extracted from the pellet using the Qiagen Viral RNA extraction kit (Qiagen, Belgium) according to the manufacturer's instructions. Viral cDNA was synthesized in a one-step RT-PCR reaction using forward primer KVL008 and reverse primer KVL009 [48] in $50 \mu \mathrm{l}$ mix containing $5 \mu \mathrm{l}$ viral RNA, $20 \mu \mathrm{M}$ of each primer, $1 \mu \mathrm{l}$ SuperScript III One-Step RT-PCR with Platinum Taq High Fidelity mix and 8 units RNAseOUT (all from Invitrogen, Merelbeke, Belgium) under the following conditions: initial denaturation at $94^{\circ} \mathrm{C}$ for 2 mins and 40 amplification cycles $\left(94^{\circ} \mathrm{C}\right.$ for $15 \mathrm{~s}, 60^{\circ} \mathrm{C}$ for $30 \mathrm{~s}, 68^{\circ} \mathrm{C}$ for $\left.4 \mathrm{mins}\right)$ followed by a final 10 mins extension step at $68^{\circ} \mathrm{C}$. $2 \mu \mathrm{l}$ of the amplified cDNA was further amplified using forward primer MM1 FP (5'-GCGTTAGGCATCTCTTATGGCAGGAAGAAG-3') 
Table 1. Characteristics of phenotypic assays developed for determination of HIV-1 coreceptor usage.

\begin{tabular}{|c|c|c|c|c|c|c|c|c|}
\hline Assay & & System & Env target & Producer cells & Target cells & readout & $\begin{array}{l}\text { Detection } \\
\text { limit }\end{array}$ & reference \\
\hline & ESTA & Pseudovirions & Full Env & Hek293T & U87.CD4.R5/R4 & Luciferase & $0.3 \% \times 4$ & [30] \\
\hline & Virco & $\begin{array}{l}\text { Recombinant viral } \\
\text { particles }\end{array}$ & gp120 (NH2-V4) & Hek293T & U87.CD4.R5/R4 & eGFP & $<10 \% \times 4$ & [32] \\
\hline \multirow[t]{3}{*}{$\begin{array}{l}\text { Commercial } \\
\text { assays }\end{array}$} & Phenoscript & $\begin{array}{l}\text { Recombinant viral } \\
\text { particles }\end{array}$ & V1-V3 & Hek293T & U373MG.CD4.R5/X4 & $\beta$-Galactosidase & $5-10 \%$ X4 & [34] \\
\hline & PhenXR & $\begin{array}{l}\text { Recombinant viral } \\
\text { particles }\end{array}$ & V1-V3 & HeLa & SX22-HeLaR5/X4 & $\beta$-Galactosidase & $1 \% \times 4$ & [71] \\
\hline & $\begin{array}{l}\text { Toulouse tropism } \\
\text { test (TTT) }\end{array}$ & $\begin{array}{l}\text { Recombinant viral } \\
\text { particles }\end{array}$ & Env Ectodomain & Hek293T & U87.CD4.R5/R4 & Luciferase & $0.5 \% \times 4$ & [35] \\
\hline \multirow[t]{5}{*}{$\begin{array}{l}\text { Non- } \\
\text { commercial } \\
\text { assays }\end{array}$} & & $\begin{array}{l}\text { Recombinant viral } \\
\text { particles }\end{array}$ & Full Env & Hek293T & $\begin{array}{l}\text { U87.CD4.R5/R4 or } \\
\text { GHOST. } \\
\text { CD4.R5/X4 }\end{array}$ & Luciferase & $1 \% \times 4$ & [72] \\
\hline & & Pseudovirions & Full Env & Hek293T & U87.CD4.R5/R4 & Luciferase & $\begin{array}{l}1 \% \text { X4 (high } \\
\text { VL) }\end{array}$ & [33] \\
\hline & & & & & & & $5 \%$ X4 (low VL) & \\
\hline & CRP Env-RVA & $\begin{array}{l}\text { Recombinant viral } \\
\text { particles }\end{array}$ & Env ectodomain & Hek293T & U87.CD4.R5/R4 & Luciferase & $2.5 \% \times 4$ & \\
\hline & & & & & & & $5 \%$ R5 & \\
\hline
\end{tabular}

Abbreviations: ESTA: Enhanced Sensitivity Trofile Assay; Env: Envelope; eGFP: enhanced Green Fluorescent protein; X4: CXCX4-using strains; R5:CCR5-using strains. doi:10.1371/journal.pone.0060566.t001

and reverse primer rec HR1-2_RP (5'-CTCTCTCTfCGACGTTCTTCTTC- $3^{\prime}$ ) [27] in a $50 \mu \mathrm{l}$ reaction mix containing $2 \mathrm{mM} \mathrm{MgSO}_{4}, 0.2 \mathrm{mM}$ of each dNTP, $20 \mu \mathrm{M}$ of each primer, 2.5 Units Platinum Taq High Fidelity DNA polymerase. The amplification conditions were: initial denaturation step at $95^{\circ} \mathrm{C}$ for $3 \mathrm{~min}$, 35 cycles of denaturation at $95^{\circ} \mathrm{C}$ for $30 \mathrm{~s}$, annealing at $48^{\circ} \mathrm{C}$ for $30 \mathrm{~s}$, extension at $68^{\circ} \mathrm{C}$ for $3 \mathrm{~min}$, and a final extension step at $68^{\circ} \mathrm{C}$ for $10 \mathrm{~min}$. Amplification was verified by agarose gel electrophoresis. To avoid PCR selection, five independent amplifications were performed in parallel for each sample and were pooled for recombinant virus production and sequencing.

\section{Sequencing}

To circumvent a potential primer-linked bias, the V3-loop was sequenced directly from the same Env ectodomain amplicon used to produce Env-recombinant viruses (Fig. 1). Sequencing was performed using the BigDye Terminator v3.1 dye on Applied Biosystems 3500 xL DX genetic analyzer (Applied Biosystems Europe BV, Belgium), using sense primers 6951 and 6990 and reverse primers 7336 [49]. For sequencing of viral supernatants, viral RNA was extracted and amplified as described previously and a nested PCR was performed using $2 \mu$ of the Env cDNA, using primers KKl [50] and DR8 [51] (400 nM each) in a mix containing $5 \mu \mathrm{l} 10 \times$ PCR Gold Buffer II, $20 \mu \mathrm{M}$ dNTPs, $200 \mu \mathrm{M}$ $\mathrm{MgCl} 2$ and $0.5 \mu \mathrm{l}$ AmpliTaq Gold DNA polymerase (Applied Biosystems), in the following cycling conditions: denaturing for 10 mins at $95^{\circ} \mathrm{C}$, followed by 40 amplification cycles $\left(15 \sec 95^{\circ} \mathrm{C}\right.$, $30 \sec 55,5^{\circ} \mathrm{C}, 1 \mathrm{~min} 72^{\circ} \mathrm{C}$ ) and a final 10 mins extension step at $72^{\circ} \mathrm{C}$. For those viral supernatants that could not be sequenced using this method because of inadequate viral content, the viral RNA was amplified and sequenced using primers KK1 and DR8 (400 nM each) in a one-step RT-PCR reaction containing $10 \mu \mathrm{l}$ viral RNA, $1.5 \mu \mathrm{l}$ of each primer, $10 \mu \mathrm{l} 5 \times$ buffer, $40 \mu \mathrm{M}$ dNTPs, $0.1 \mu \mathrm{l}$ RNAse inhibitor and $2 \mu \mathrm{l}$ Qiagen Taq (Qiagen), as follows: RT: 30 mins at $50^{\circ} \mathrm{C}$, denaturation: 15 mins $95^{\circ} \mathrm{C}, 40$ cycles of amplification $\left(15 \sec 95^{\circ} \mathrm{C}, 30 \sec 55.5^{\circ} \mathrm{C}, 1 \min 72^{\circ} \mathrm{C}\right)$ and a final 5 min extension step at $72^{\circ} \mathrm{C}$, followed by an inner PCR using the same conditions as above. V3-loop sequences are available under EMBL Nucleotide Sequence Database with accession numbers: HE972342-HE972511 and JN407569, JN407585, JN407591, JN407601, JN407602, JN407608, JN407609, JN407611, JN407624, JN407629, JN407632, JN407661， JN407676, JN407696, JN407704, JN407706, JN407709, JN407713, JN407726, JN407738, JN407740, JN407745, JN407747, JN407805, JN407808, JN407810, JN407813, JN407814, JN407816, JN407817, JN407836, JN407872, JN407949, JN407971，JN407987，JN407991，JN408004， JN408005, JN408022, JN408023, JN408027, JN408043 and JN408058.

\section{Genotyping}

The V3 nucleotide sequences were submitted to the Geno2Pheno $_{[\text {coreceptor] }}$ algorithm (http://coreceptor.bioinf.mpi-inf.mpg. de) setting the FPR set at $5 \%, 10 \%, 15 \%$ and $20 \%$ and to webPSSM (http://indra.mullins.microbiol.washington.edu/ $\mathrm{PSSM} /$ ) using the X4/R5 matrix. The webPSSM subtype $\mathrm{C}$ SINSI matrix was used sor subtype $\mathrm{C}$. When mixtures were present in the viral population, all possible combinations were submitted independently to webPSSM and the results were reported as numbers of R5, X4 or R5/X4 clones for comparison with the phenotypic assay.

\section{Production of Recombinant Viruses}

pNL4.3AEG.Luc has been described elsewhere [27]. Briefly, pNL4.3AEG.Luc is a NL4-3-derived plasmid deleted of the Env ectodomain (6225-8314), containing a AfeI restriction site in the place of Env for linearization and harboring a firefly luciferase gene in the place of nef. For Env-recombinant viral production, $70 \%$ confluent HEK293T cells were co-transfected with Afe Ilinearized pNL4.3AEG.Luc (Westburg, Netherlands) and patient-derived Env PCR amplicons using Lipofectamine 2000 (Invitrogen, Merelbeke, Belgium) according to manufacturer's instructions. HIV-1 NL4-3 (X4) and NL-AD8 (R5) were used as positive controls. Cell-free culture supernatants were collected 48 


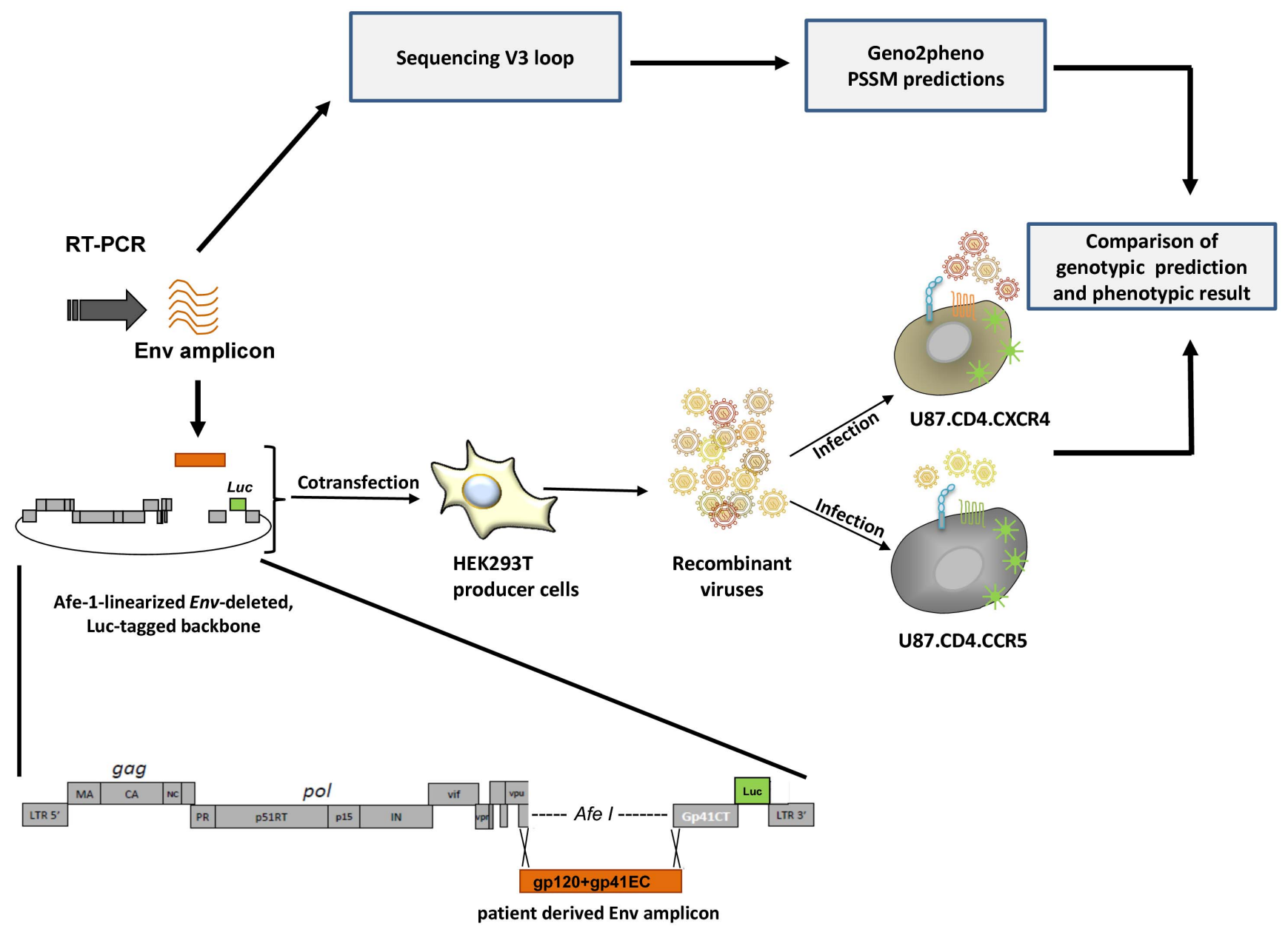

Figure 1. Study design/RVA design. Viral RNA was extracted from patient plasma RT-PCR amplified. Env amplicons spanning the Env ectodomain were further amplified through an inner PCR. Five independent PCRs were pooled to minimize PCR-selection. Recombinant viruses were produced by co-transfecting HEK293T cells with Afe I-linearized, luciferase-tagged, Env-deleted, viral backbone and patient-derived PCR amplicon. Normalized amounts of recombinant viruses were used to infect U87.CD4.CCR5 or U87.CD4.CXCR4 indicator cells. Infection was monitored by quantifying luminescence in the cell lysates. Depending on the outcome of the infection, viruses were classified as either CCR5 tropic, CXCR4 tropic or dual/ mixed. The same patient-derived PCR amplicon used for viral production was sequenced and tropism inferred by Geno2Pheno ${ }_{\text {[coreceptor] }}$ and webPSSM algorithms. The phenotypic and genotypic results were compared. Abbreviations: Env EC: Env ectodomain; gp41-TM-CT: gp41 Transmembrane+cytoplasmic tail. doi:10.1371/journal.pone.0060566.g001

hours post-transfection, clarified by centrifugation and stored at $-80^{\circ} \mathrm{C}$ until use (Fig. 1). Viral production was determined by quantifying p24 capsid protein using a p24 ELISA test (Perkin Elmer, Amsterdam, Netherlands). Virus lacking an envelope produced by transfecting the sole linearized backbone was used to assess background noise.

\section{Env Recombinant Viral Assay}

$10^{4}$ U87.CD4.CGR5 or U87.CD4.CXCR4 cells in 96-well plates were infected with Env-recombinant viruses (200 pg p24, quantified by Perkin Elmer kit) by spinoculation at $1200 \times \mathrm{g}$ for 2 hours at $25^{\circ} \mathrm{C}$ [52], followed by incubation for 1 hour at $37^{\circ} \mathrm{C}$. Medium was replaced and cells were cultured for a further 48 hours, after which luciferase activity was assayed using the Promega Luciferase assay kit (Promega, Leiden, Netherlands) according to manufacturer's instructions. Luminescence readout was performed on a Tecan microplate reader (Tecan, Switzerland) over one second exposure. All infections were performed in triplicate. Recombinant viruses were scored as positive for the specific coreceptor if the luciferase signal was at least twice the background.

Where used, $1 \mu \mathrm{M}$ Maraviroc (CCR5 antagonist) or $1 \mu \mathrm{M}$ AMD3100 (CXCR4 antagonist) were added to the cells, the plate was centrifuged at $400 \times \mathrm{g}$ for $10 \mathrm{mins}$ at $25^{\circ} \mathrm{C}$ and incubated at $37^{\circ} \mathrm{C}$ for 15 mins prior to addition of the recombinant viruses and spinoculation.

\section{Trofile ESTA}

19 samples (5 subtype B, 2 subtype A1, 2 subtype C, 1 subtype D, 3 CRF01_AE, 6 CRF02_AG) for which phenotypic results differed from the Geno2Pheno ${ }_{[\text {coreceptor] }}$-inferred results and for which plasma was available were tested in the Trofile ${ }^{\circledR}$ ESTA.

\section{Statistical Analyses}

In this study, we did not assume the RVA nor the genotypic prediction tools to be the reference test to determine viral tropism, therefore concordance and Cohen kappa values were assessed using Statools (www.stattools.net). Concordance between the 
phenotypically measured and genotypically predicted tropism was calculated as follows for each subtype or group of subtypes: Concordance $=$ Number of samples with the same tropism by both assays/Total number of samples tested $\times 100$. The correlation between tests is usually considered good when kappa $>0.6$. Tropism measured using the RVA was considered to be concordant with Geno2Pheno ${ }_{\text {[coreceptor] }}$ prediction if they both detected pure $\mathrm{R} 5$ or pure $\mathrm{X} 4$. When dual/mixed strains were detected using the RVA, they were considered to be concordant with an X4 genotypic prediction and discordant with a R5 prediction, as Geno2Pheno only predicts the presence of $\mathrm{X} 4$ strains. For comparison with webPSSM, results were considered to be concordant if both assays provided the same result, i.e. R5, X4, or Mixed (D/M). D/M samples detected as a purely X4 or purely R5 sample by the other test were considered to be discordant. Sensitivity and specificity were calculated using GraphPad Prism version 5, setting the phenotypic results as 'true'.

\section{Results}

\section{Detection of Minority Variants}

To determine the threshold for detecting minority variants, mixtures containing known proportions of pNLAD8 (R5) and of pNL4-3 (X4) were PCR-amplified and used to produce R5/X4 mixed Env recombinant viruses. U87.CD4.CGR5 and U87.CD4.CXCR4 indicator cells were infected with 2-fold serial dilutions of the recombinant NLAD8:NL4-3 mixtures (20 pg to $12.5 \mathrm{pg}$ ). As reported in Fig. 2A, 2.5\% NL4-3 (X4) minority variants could be detected for NL4-3 with signals higher than 200,000 RLU and 5\% NL4-3 variants were detectable with pure NL4-3 signals higher than 50,000 RLU. NLAD8 (R5) minority variants were detected down to $5 \%$ at the highest viral input and $10 \%$ for control values above 50,000 RLU (Fig. 2B). In this study, experiments were included if positive controls (pure NLAD8 and NL4-3) generated infection signals above 50,000 RLU.

\section{Production of Patient-derived Env-recombinant Viruses}

Overall PCR amplification success of patient-derived Envs was 87\% (254/292 samples included) (Table 2). Amplification success was dependent on both subtype and VL. For subtypes Al, B, C, G, and CRF01_AE and CRF02_AG, amplification was achieved in $83.3-100 \%$ of cases, while for subtypes D and F, amplification was successful in $66.7 \%$ and $46.7 \%$ of cases respectively (Table 2). Of note, for some subtypes (D, F) few samples were available (15) inflating the relative weight of failed amplification compared to the overall rate. Both viral load ( $\mathrm{VL}<1,000 \mathrm{RNA}$ copies/mL) and non-B subtype compromised amplification success: the use of subtype-specific primers designed to target the most conserved regions of env and based on the most frequent polymorphisms did not improve these figures further (data not shown). When stratified for viral load, amplification succeeded in $94.9 \%$ of cases for $\mathrm{VL}>100,000$ RNA copies/mL, $89.7 \%$ of cases for VL between 10,001-100,000 RNA copies/mL, 83.8\% of cases for VL between $1,000-10,000$ RNA copies $/ \mathrm{mL}$ and decreased to $70 \%$ for $\mathrm{VL}<1,000$ RNA copies/mL (Fig. 3). Recombinant viruses could be produced for 231 Envs, as determined by p24 antigen ELISA in the viral supernatant. Of those, $91.3 \%$ were infectious and tropism was tested (Table 2).

\section{Concordance of Env-RVA with Genotypic Prediction}

Tropism determined phenotypically using the Env-RVA was compared to tropism inferred by the Geno2Pheno ${ }_{[\text {coreceptor] }}$ and webPSSM prediction algorithms based on the V3-loop sequence. These two algorithms were chosen among all available genotyping tools because they are the most widely used in the clinic. Results are reported in Table 2. Overall, concordance between the phenotypically measured tropism (RVA) and Geno2pheno ${ }_{\text {[corecep- }}$ tor] (10\% FPR cutoff) was $85.2 \%$ and concordance of the RVA with webPSSM was $79.5 \%$ (Table 2). The overall Cohen kappa value for comparison with Geno2Pheno was 0.6252, ranging from 0.3226 (CRF01_AE) to 0.9180 (subtype G) (Table 2), reflecting good concordance of the phenotypic measure with genotypic prediction. Overall kappa value for comparison of phenotypically measured tropism with webPSSM was lower (0.4544), ranging from 0.0745 (CRF02_AG) to 0.6190 (subtype C with webPSSM subtype $\mathrm{C}$ ). If detection of the presence of $\mathrm{X} 4$ strains is considered rather than full concordance between the phenotype and the genotype inferred by webPSSM, then concordance between these two assays increased to $83.3 \%$ (not shown) and Cohen kappa value reached 0.5240 , ranging from 0.1509 (subtype A1) to 0.8262 (subtype G) (Table 2). Among discordant samples, in 14 cases the outcome of both prediction algorithms was identical but disagreed with the phenotypic result, while in the remaining cases, the phenotypically measured tropism disagreed with one algorithm only (Table 3). Decreasing the Geno2Pheno ${ }_{[\text {coreceptor] }}$ FPR cutoff to $5 \%$ (less sensitive to detect $\mathrm{X} 4$ ) increased concordance to $91.4 \%$, as expected, while augmenting the FPR to $15 \%$ and $20 \%$ lowered concordance to $81.0 \%$ and $79.5 \%$ respectively (Table 2 ).

For all discordant results (FPR cutoff up to 20\% for Geno2Pheno $_{\text {[coreceptor] }}$ and webPSSM) for which enough material was available (50/74 samples) the phenotypic assay was repeated using CGR5 and CXCR4 inhibitors $(1 \mu \mathrm{M}$ Maraviroc and $1 \mu \mathrm{M}$ AMD3100 respectively) (not shown). In all but two cases, the use of coreceptor inhibitors confirmed tropism. In one case, detection of $\mathrm{X} 4$ minority variants was close to the limit of detection and was not confirmed in the repeated experiment. In the second case, a strictly R5 strain by phenotypic measure and webPSSM, Maraviroc inhibited infection by 3 logs but did not fully inhibit entry in U87.CD4.CCR5 cells. To rule out the possibility that an intrinsic bias in the recombination step of the RVA would result in selection of some strains and in failure to detect some minority $\mathrm{X} 4$ strains, we sequenced the V3-loop of Env-recombinant viral particles used to infect U87 indicator cells. For all re-tested samples (50), the V3-loop sequence of recombinant viral supernatants was identical to the V3-loop of the parental PCR amplicon used to produce the recombinant viruses, and when submitted to Geno2Pheno ${ }_{[\text {coreceptor] }}$, a similar or identical FPR was obtained (data not shown), strongly arguing against the hypothesis of a selection due to the recombination process while generating recombinant viruses. Further, for 18 discordant samples, tropism was determined using the Trofile ESTA, which is based on pseudovirions rather than on recombination. Tropism measured using the Trofile ESTA confirmed the RVA results in 16/18 positive tests (Table 3). In one case (CRF01_AE) the RVA failed to detect a minority $\mathrm{X} 4$ strain, reflecting the low infectivity of this recombinant, whereas in the second case (CRF02_AG), the RVA detected the presence of low $\mathrm{X} 4$ variants which were undetectable using the Trofile ESTA, potentially a consequence of PCR selection due to the sample's plasma viral load being near the limit validated for the assay.

\section{Characterization of Discordant Outcomes}

Most discordant cases involved non-B subtypes for Geno2Pheno [coreceptor] $(10 \% \mathrm{FPR})(5.6 \%$ discordant cases for subtype B, Cohen kappa $=0.8591$, versus $17.9 \%$ for non-B subtypes, Cohen kappa $=0.5446$ ), but not for webPSSM, for which 20.4\% (Cohen kappa $=0.3926)$ and 20.5\% (Cohen kappa $=0.4734)$ discordant cases were recorded for subtype $\mathrm{B}$ and for non-B subtypes 
A

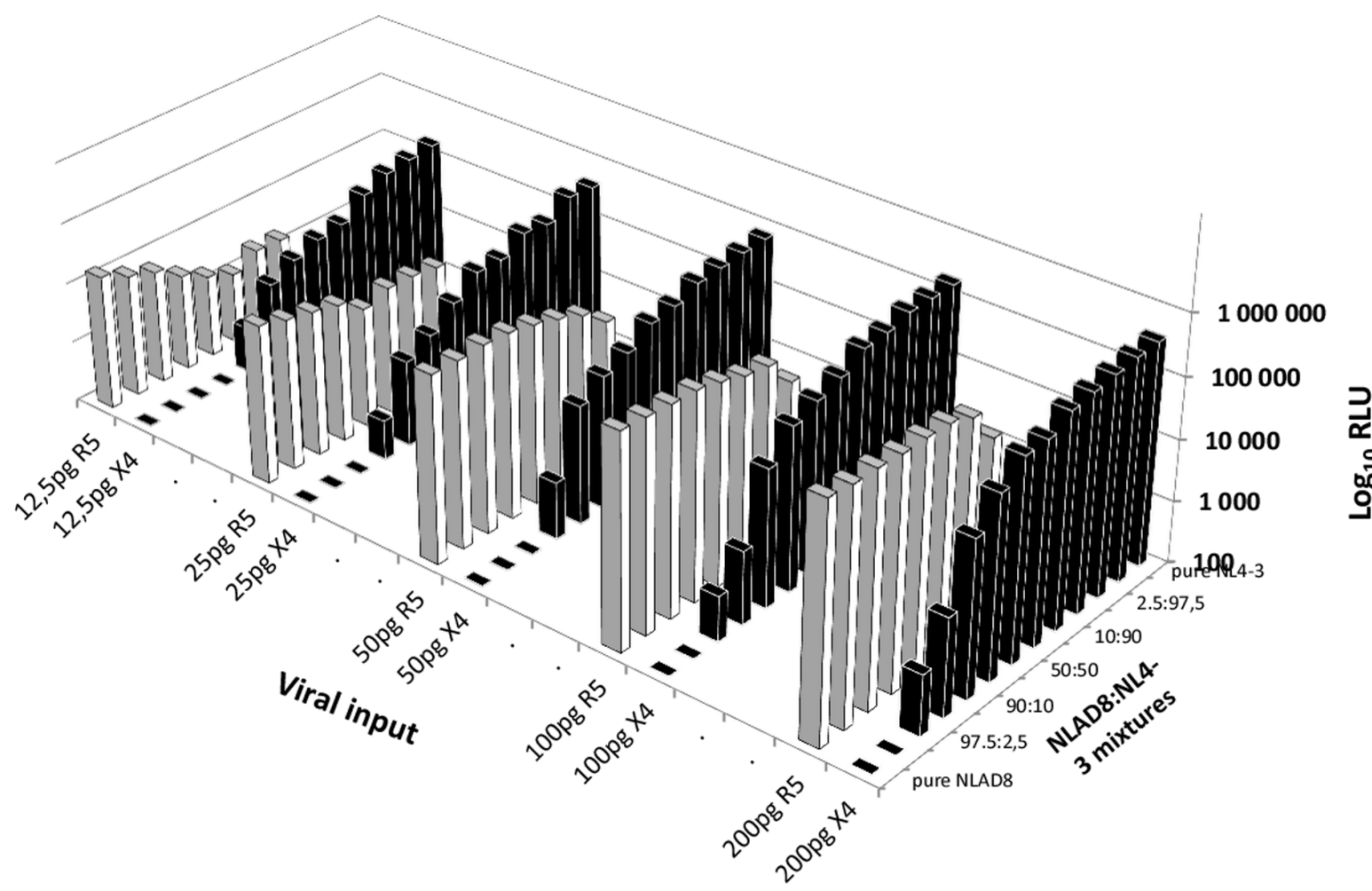

B

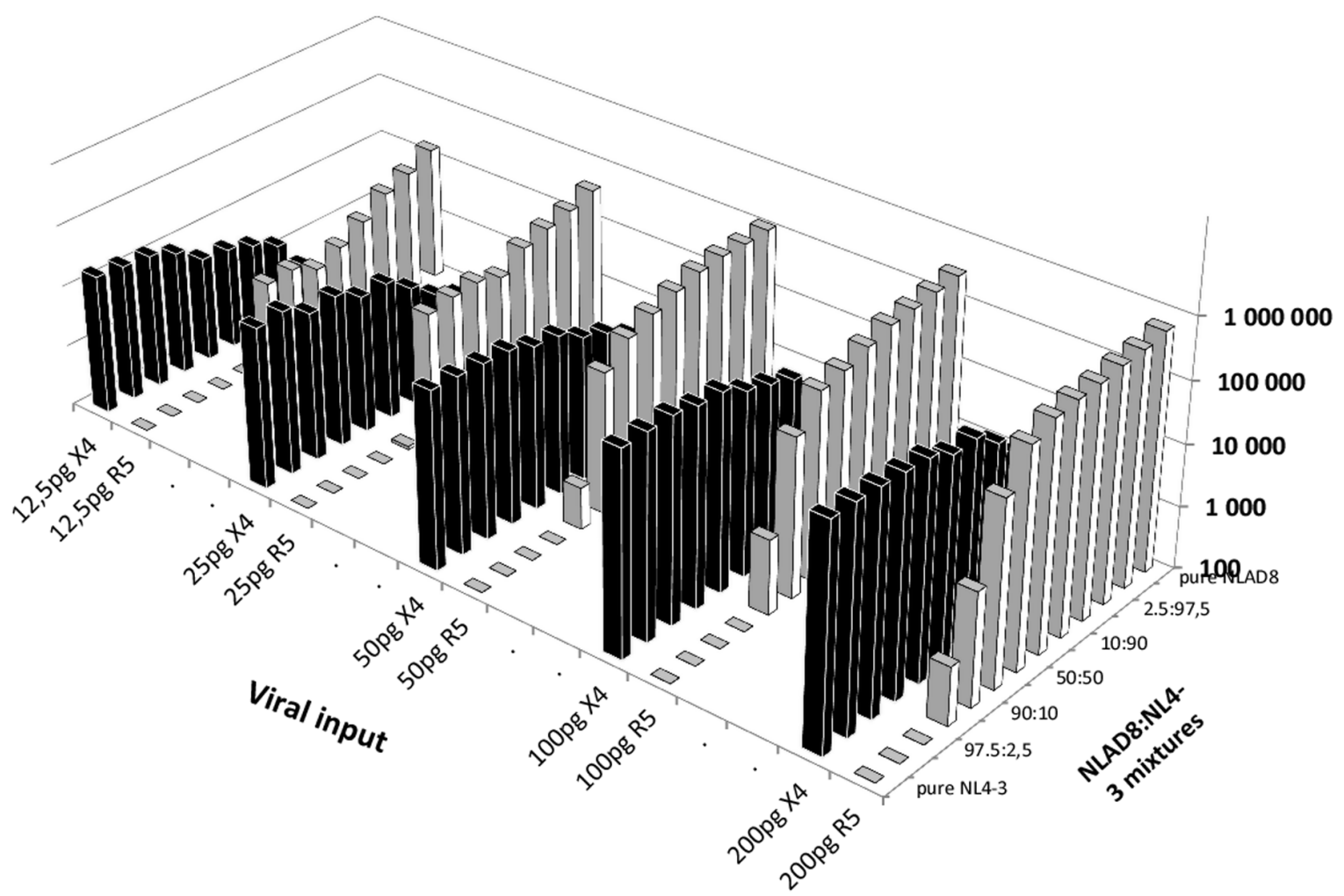

Figure 2. Detection of minority CXCR4 and CCR5 using variants within mixed viral populations. Mixtures containing known proportions of pNLAD8 and pNL4-3 (100:0, i.e. pure NLAD8, 99:1, 97.5:2.5, 95:5, 90:10, 80:20,50:50, 20:80, 10:90, 5:95, 2.5:97.5, 1:99, 0:100, i.e. pure NL4-3) were PCR-amplified and used to generate recombinant viruses. U87.CD4.CCR5 and U87.CD4.CXCR4 indicator cells were infected with serial 2-fold dilutions (x-axis) of mixtures (z-axis) to determine the threshold for detection of minority variants. Infection was quantified 48 hours after infection by measuring luciferase activity in cell lysates (y-axis). Black bars report infection of U87.CD4.CXCR4 cells and grey bars report infection of U87.CD4.CCR5 cells. Panels A and B report the same data, oriented to focus on NL4-3 minority variants (A) or on NLAD8 minority variants (B). doi:10.1371/journal.pone.0060566.g002 


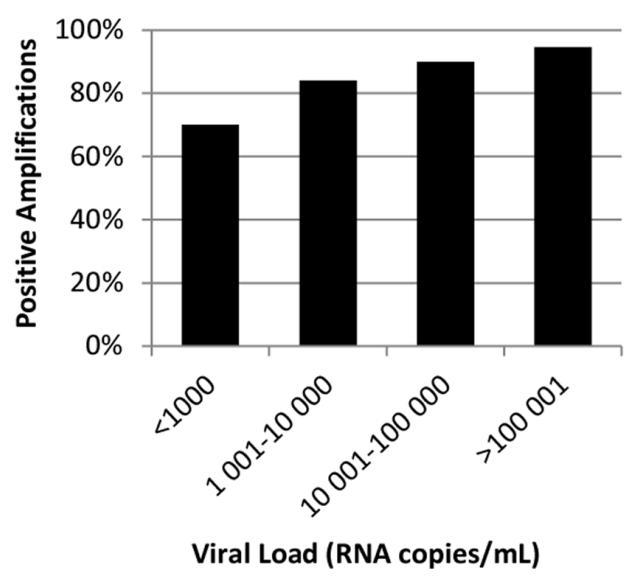

Figure 3. Distribution of PCR amplification success stratified by viral load. The Env ectodomain was amplified from plasma viral RNA by a one-step RT-PCR followed by an inner PCR. Five independent PCR amplifications were pooled to minimize primer-related selection. 292 samples from patients infected with HIV subtypes A1, B, C, D, F, G, CRF01_AE and CRF02_AG were included. Viral load ranged from 466 to $1,350,000$ RNA copies/mL.

doi:10.1371/journal.pone.0060566.g003

respectively (Table 2, Fig. 4). For Geno2Pheno ${ }_{[\text {coreceptor] }}$, the highest kappa values were recorded for subtypes $\mathrm{G}$ and $\mathrm{B}$, and the lowest value for CRF01_AE. For webPSSM, good kappa values were recorded for subtypes $\mathrm{C}$ (using the webPSSM subtype $\mathrm{C}$ matrix); using the subtype B X4/R5 matrix, good kappa values were also seen for subtypes D, G, F and CRF01_AE, intermediate for subtypes B, and poor for subtypes Al and CRF02_AG (Table 2). Of note, kappa values increased to 0.4752 for subtype B when detection of $\mathrm{X} 4$ strains was compared rather than absolute concordance (i.e. $\mathrm{D} / \mathrm{M}$ and $\mathrm{D} / \mathrm{M}, \mathrm{X} 4$ and $\mathrm{X} 4$ ), probably reflecting tuning of the algorithm for the detection of $\mathrm{X} 4$ strains.

The sensitivity and specificity of Geno2Pheno ${ }_{[\text {coreceptor] }}$ and PSSM with respect to the recombinant viral assay (setting the phenotypic measure as 'true') was calculated: overall sensitivity and specificity were $88.9 \%$ and $84.2 \%$ for Geno2Pheno ${ }_{\text {[coreceptor] }}$ $(10 \%$ FPR cutoff) and $65.2 \%$ and $88.4 \%$ for webPSSM (considering the ability to detect the presence of $\mathrm{X} 4$ variants) (data not shown). For subtype B strains, sensitivity and specificity were $100 \%$ and $92.7 \%$ respectively for Geno $2 \mathrm{Pheno}_{\text {[coreceptor]; }}$ for webPSSM, sensitivity and sensitivity were $46.1 \%$ and $95.1 \%$ respectively (data not shown). For non-B subtypes, sensitivity was $84.4 \%$ for Geno $2 P_{\text {Pheno }}[$ coreceptor] and $72.7 \%$ for webPSSM (data not shown). Specificities ranged from $50 \%$ to $100 \%$ for Geno2Pheno ${ }_{\text {[coreceptor] }}$ and from 50 to $100 \%$ for webPSSM (data not shown), in line with previous reports [53-57].

For subtype B samples, Geno2Pheno ${ }_{[\text {coreceptor] }}$ overestimated $\mathrm{X} 4$ usage for all 3 discordant samples. In contrast, webPSSM failed to detect CXCR4 usage for 7/11 samples (Table 3). Neither viral load nor the presence of mixtures could account for failure to detect X4 minor strains. For non-B subtypes, Geno2Pheno ${ }_{[\text {cor- }}$ eceptor] predicted CXCR4 usage while the phenotypic assay identified strictly R5 strains in most cases, and particularly for CRF01_AE (12/14 cases) and CRF02_AG (6/7) (Table 3). Such skewing towards overestimating the presence of $\mathrm{X} 4$ minority variants for these CRFs was maintained when the FPR cut-off was shifted, although these observations did not reach statistical significance using a Fisher's exact test $(\mathrm{p}<0.05)$. Disagreement of the phenotypically measured tropism with webPSSM was observed chiefly for subtype Al (40\% disagreement) and CRF01_AE (28.2\% disagreement). For CRF01_AE, webPSSM predicted CXCR4 usage while the phenotypic RVA reported strictly R5 strains in 7/11 cases, and in 2/11 cases, CXCR4 usage detected phenotypically was missed by webPSSM (Table 3). For

Table 2. Distribution of samples, phenotyping and genotyping, and concordance between phenotypic and genotypic tropism.

\begin{tabular}{|c|c|c|c|c|c|c|c|c|c|c|c|c|c|c|c|c|}
\hline \multicolumn{2}{|l|}{ Samples } & \multicolumn{2}{|c|}{ Env PCR } & \multicolumn{2}{|c|}{ RVA result } & \multicolumn{2}{|c|}{$\begin{array}{l}\text { V3 loop } \\
\text { sequence }\end{array}$} & \multirow[t]{2}{*}{$\begin{array}{l}\text { Pheno/ } \\
\text { geno } \\
\text { paired } \\
\text { results }\end{array}$} & \multicolumn{5}{|c|}{ Concordance of RVA with } & \multicolumn{3}{|c|}{ Cohen kappa values } \\
\hline Subtype & $\mathbf{N}$ & $\mathbf{N}$ & $\%$ & $\mathbf{N}$ & $\%$ & $\mathbf{N}$ & $\%$ & & $\begin{array}{l}\text { G2P: } \\
\mathbf{5 \%}\end{array}$ & $\begin{array}{l}\text { G2P: } \\
10 \%\end{array}$ & $\begin{array}{l}\text { G2P: } \\
15 \%\end{array}$ & $\begin{array}{l}\text { G2P: } \\
20 \%\end{array}$ & PSSM & $\begin{array}{l}\text { G2P: } \\
10 \%\end{array}$ & PSSM & $\begin{array}{l}\text { PSSM } \\
\text { X4 }\end{array}$ \\
\hline A1 & 17 & 17 & $100.0 \%$ & 17 & $100.0 \%$ & 15 & $88.2 \%$ & 15 & $93.3 \%$ & $86.7 \%$ & $73.3 \%$ & $73.3 \%$ & $60.0 \%$ & 0.4444 & 0.1743 & 0.1509 \\
\hline B & 73 & 62 & $84.9 \%$ & 62 & $100.0 \%$ & 54 & $87.1 \%$ & 54 & $100.0 \%$ & $94.4 \%$ & $90.7 \%$ & $88.9 \%$ & $79.6 \%$ & 0.8591 & 0.3926 & 0.4752 \\
\hline C & 21 & 21 & $100.0 \%$ & 21 & $100.0 \%$ & 20 & $95.2 \%$ & 20 & $90.0 \%$ & $90.0 \%$ & $85.0 \%$ & $80.0 \%$ & $90.0 \% *$ & 0.6078 & $0.6190^{*}$ & $0.6078^{*}$ \\
\hline D & 15 & 10 & $66.7 \%$ & 10 & $100.0 \%$ & 7 & $70.0 \%$ & 7 & $85.7 \%$ & $71.4 \%$ & $71.4 \%$ & $71.4 \%$ & $85.7 \%$ & 0.3636 & 0.6111 & 0.5882 \\
\hline$F$ & 15 & 7 & $46.7 \%$ & 7 & $100.0 \%$ & 6 & $85.7 \%$ & 6 & $83.3 \%$ & $83.3 \%$ & $83.3 \%$ & $66.7 \%$ & $83.3 \%$ & 0.5714 & 0.5714 & 0.5714 \\
\hline G & 55 & 52 & $94.5 \%$ & 44 & $84.6 \%$ & 42 & $80.8 \%$ & 40 & $100.0 \%$ & $97.5 \%$ & $95.0 \%$ & $95.0 \%$ & $87.5 \%$ & 0.9180 & 0.5910 & 0.8268 \\
\hline CRF01_AE & 42 & 40 & $95.2 \%$ & 39 & $97.5 \%$ & 40 & $100.0 \%$ & 39 & $79.5 \%$ & $64.1 \%$ & $61.5 \%$ & $61.5 \%$ & $71.8 \%$ & 0.3226 & 0.5153 & 0.5351 \\
\hline CRF02_AG & 54 & 45 & $83.3 \%$ & 32 & $71.1 \%$ & 30 & $66.7 \%$ & 29 & $82.8 \%$ & $79.3 \%$ & $72.4 \%$ & $72.4 \%$ & $79.3 \%$ & 0.4494 & 0.0745 & 0.2077 \\
\hline All non-B & 219 & 192 & $87.7 \%$ & 170 & $88.5 \%$ & 160 & $83.3 \%$ & 156 & $88.5 \%$ & $82.1 \%$ & $77.6 \%$ & $76.3 \%$ & $79.5 \%$ & 0.5446 & 0.4734 & 0.5411 \\
\hline Total & 292 & 254 & $87.0 \%$ & 232 & $91.3 \%$ & 214 & $84.3 \%$ & 210 & $91.4 \%$ & $85.2 \%$ & $81.0 \%$ & $79.5 \%$ & $79.5 \%$ & 0.6252 & 0.4544 & 0.5240 \\
\hline
\end{tabular}

Distribution of samples per subtype, successful Env PCR amplification, recombinant virus production and sequencing of the V3-loop, and results (concordance and Cohen kappa values) for genotype/phenotype pairs are reported.

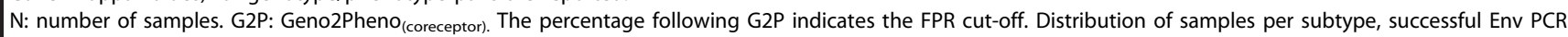
amplification, recombinant virus production and sequencing of the V3-loop, and results (concordance and Cohen kappa values) for genotype/phenotype pairs are reported.

*For subtype C, concordance was determined and with webPSSM subtype C SINSI. Concordance with webPSSM X4/R5 was 75\% and Cohen kappa values were poor ( -0.0989 for full agreement and -0.1365 when detection of $\mathrm{X} 4$ strains was considered).

doi:10.1371/journal.pone.0060566.t002 
Table 3. Detail of discordant results between RVA, ESTA, Geno2Pheno (coreceptor) $_{\text {and }}$ webPSSM.

\begin{tabular}{|c|c|c|c|c|c|c|c|c|c|c|}
\hline \multirow[t]{2}{*}{ HIV-1 subtype } & \multirow[t]{2}{*}{ RVA result } & \multirow[t]{2}{*}{$\begin{array}{l}\text { Trofile } \\
\text { result }\end{array}$} & \multicolumn{5}{|l|}{ G2P } & \multirow{2}{*}{ webPSSM } & \multicolumn{2}{|c|}{ Discordance } \\
\hline & & & $5 \%$ cutoff & $10 \%$ cutoff & f $15 \%$ cutoff & $20 \%$ cutoff & FPR & & G2P & PSSM \\
\hline A1 & R5 & R5 & R5 & $\mathrm{X} 4$ & $\mathrm{X} 4$ & $\mathrm{X} 4$ & 6.8 & $\mathrm{X} 4$ & G2P 10\% & PSSM \\
\hline A1 & R5 & $\mathrm{N} / \mathrm{A}$ & R5 & $\mathrm{X} 4$ & $\mathrm{X} 4$ & $\mathrm{X} 4$ & 8.5 & $\mathrm{D} / \mathrm{M}$ & G2P $10 \%$ & PSSM \\
\hline A1 & R5 & R5 & R5 & R5 & $\mathrm{X} 4$ & $\mathrm{X} 4$ & 10.5 & $\mathrm{X} 4$ & G2P 15\% & PSSM \\
\hline A1 & R5 & $N / A$ & R5 & R5 & R5 & R5 & 42.2 & $\mathrm{D} / \mathrm{M}$ & agree & PSSM \\
\hline A1 & R5 & $\mathrm{N} / \mathrm{A}$ & R5 & R5 & R5 & R5 & 40.3 & $\mathrm{X} 4$ & agree & PSSM \\
\hline A1 & R5 & $\mathrm{N} / \mathrm{A}$ & R5 & R5 & R5 & R5 & 22.6 & $\mathrm{D} / \mathrm{M}$ & agree & PSSM \\
\hline B & R5 & R5 & R5 & $\mathrm{X} 4$ & $\mathrm{X} 4$ & $\mathrm{X} 4$ & 6.7 & R5 & G2P 10\% & agree \\
\hline B & R5 & failed & R5 & $\mathrm{X} 4$ & $\mathrm{X} 4$ & $\mathrm{X} 4$ & 6.8 & R5 & G2P 10\% & agree \\
\hline B & R5 & $\mathrm{N} / \mathrm{A}$ & R5 & R5 & $\mathrm{X} 4$ & $\mathrm{X} 4$ & 13.8 & R5 & G2P $15 \%$ & agree \\
\hline B & R5 & N/A & R5 & R5 & $\mathrm{X} 4$ & $\mathrm{X} 4$ & 10.5 & R5 & G2P 15\% & agree \\
\hline B & R5 & $N / A$ & R5 & R5 & R5 & $\mathrm{X} 4$ & 17.6 & R5 & G2P 20\% & agree \\
\hline B & R5 & R5 & R5 & $\mathrm{X} 4$ & $\mathrm{X} 4$ & $\mathrm{X} 4$ & 6.9 & R5 & G2P 10\% & agree \\
\hline B & $\mathrm{D} / \mathrm{M}$ & $\mathrm{D} / \mathrm{M}$ & $\mathrm{X} 4$ & $\mathrm{X} 4$ & $\mathrm{X} 4$ & $\mathrm{X} 4$ & 4.6 & R5 & agree & PSSM \\
\hline B & R5 & N/A & R5 & R5 & R5 & R5 & 26.2 & $\mathrm{D} / \mathrm{M}$ & agree & PSSM \\
\hline B & $\mathrm{X} 4$ & $\mathrm{~N} / \mathrm{A}$ & $\mathrm{X} 4$ & $\mathrm{X} 4$ & $\mathrm{X} 4$ & $\mathrm{X} 4$ & 0.7 & $\mathrm{D} / \mathrm{M}$ & agree & PSSM partial \\
\hline B & R5 & $\mathrm{N} / \mathrm{A}$ & R5 & R5 & R5 & R5 & 72.8 & $\mathrm{D} / \mathrm{M}$ & agree & PSSM \\
\hline B & $\mathrm{X} 4$ & $\mathrm{~N} / \mathrm{A}$ & $\mathrm{X} 4$ & $\mathrm{X} 4$ & $\mathrm{X} 4$ & $\mathrm{X} 4$ & 3.7 & R5 & agree & PSSM \\
\hline B & $\mathrm{X} 4$ & $N / A$ & $\mathrm{X} 4$ & $\mathrm{X} 4$ & $\mathrm{X} 4$ & $\mathrm{X} 4$ & 3.8 & $\mathrm{D} / \mathrm{M}$ & agree & PSSM partial \\
\hline B & $\mathrm{X} 4$ & $\mathrm{~N} / \mathrm{A}$ & $\times 4$ & $\mathrm{X} 4$ & $\mathrm{X} 4$ & $\mathrm{X} 4$ & 4.7 & R5 & agree & PSSM \\
\hline B & $\mathrm{X} 4$ & $\mathrm{~N} / \mathrm{A}$ & $\mathrm{X} 4$ & $\mathrm{X} 4$ & $\mathrm{X} 4$ & $\mathrm{X} 4$ & 3.8 & R5 & agree & PSSM \\
\hline B & $\mathrm{X} 4$ & $\mathrm{~N} / \mathrm{A}$ & $\mathrm{X} 4$ & $\mathrm{X} 4$ & $\mathrm{X} 4$ & $\mathrm{X} 4$ & 3.7 & R5 & agree & PSSM \\
\hline B & $\mathrm{X} 4$ & N/A & $\mathrm{X} 4$ & $\mathrm{X} 4$ & $\mathrm{X} 4$ & $\mathrm{X} 4$ & 3.8 & R5 & agree & PSSM \\
\hline B & $\mathrm{X} 4$ & $\mathrm{~N} / \mathrm{A}$ & $\mathrm{X} 4$ & $\mathrm{X} 4$ & $\mathrm{X} 4$ & $\mathrm{X} 4$ & 3.8 & R5 & agree & PSSM \\
\hline c & $\mathrm{D} / \mathrm{M}$ & N/A & R5 & $\mathrm{X} 4$ & $\mathrm{X} 4$ & $\mathrm{X} 4$ & 6.9 & R5 & G2P 5\% & agree \\
\hline C & R5 & R5 & R5 & $\mathrm{X} 4$ & $\mathrm{X} 4$ & $\mathrm{X} 4$ & 9.6 & R5 & G2P 10\% & agree \\
\hline C & R5 & $N / A$ & R5 & R5 & $\mathrm{X} 4$ & $\mathrm{X} 4$ & 10.9 & $\mathrm{X} 4$ & G2P 15\% & PSSM \\
\hline C & R5 & $\mathrm{N} / \mathrm{A}$ & R5 & R5 & R5 & $\mathrm{X} 4$ & 17.9 & R5 & G2P 20\% & agree \\
\hline c & $\mathrm{D} / \mathrm{M}$ & $\mathrm{N} / \mathrm{A}$ & R5 & R5 & R5 & R5 & 28.8 & R5 & G2P 5\% & PSSM \\
\hline D & R5 & R5 & $\mathrm{X} 4$ & $\mathrm{X} 4$ & $\mathrm{X} 4$ & $\mathrm{X} 4$ & 4.7 & $\mathrm{X} 4$ & G2P 5\% & PSSM \\
\hline D & R5 & R5 & R5 & $\mathrm{X} 4$ & $\mathrm{X} 4$ & $\mathrm{X} 4$ & 6.8 & R5 & G2P 10\% & agree \\
\hline G & R5 & $\mathrm{N} / \mathrm{A}$ & R5 & $\mathrm{X} 4$ & $\mathrm{X} 4$ & $\mathrm{X} 4$ & 5 & R5 & G2P 10\% & agree \\
\hline G & R5 & N/A & R5 & R5 & $\mathrm{X} 4$ & $\mathrm{X} 4$ & 13.2 & R5 & G2P 15\% & agree \\
\hline G & $\mathrm{D} / \mathrm{M}$ & $\mathrm{N} / \mathrm{A}$ & R5 & $\mathrm{X} 4$ & $\mathrm{X} 4$ & $\mathrm{X} 4$ & 6.8 & R5 & G2P 5\% & PSSM \\
\hline G & $\mathrm{D} / \mathrm{M}$ & N/A & $\mathrm{X} 4$ & $\mathrm{X} 4$ & $\mathrm{X} 4$ & $\mathrm{X} 4$ & 1.3 & $\mathrm{X} 4$ & agree & PSSM partial \\
\hline G & $\mathrm{D} / \mathrm{M}$ & $N / A$ & $\mathrm{X} 4$ & $\mathrm{X} 4$ & $\mathrm{X} 4$ & $\mathrm{X} 4$ & 1.7 & $\mathrm{X} 4$ & agree & PSSM partial \\
\hline G & $\mathrm{D} / \mathrm{M}$ & $N / A$ & $\mathrm{X} 4$ & $\mathrm{X} 4$ & $\mathrm{X} 4$ & $\mathrm{X} 4$ & 1.1 & $\mathrm{X} 4$ & agree & PSSM partial \\
\hline G & R5 & $\mathrm{N} / \mathrm{A}$ & R5 & R5 & R5 & R5 & 26.9 & $\mathrm{D} / \mathrm{M}$ & agree & PSSM \\
\hline $\mathrm{F}$ & $\mathrm{D} / \mathrm{M}$ & N/A & R5 & $\mathrm{X} 4$ & $\mathrm{X} 4$ & $\mathrm{X} 4$ & 6.9 & $\mathrm{D} / \mathrm{M}$ & G2P 5\% & agree \\
\hline $\mathrm{F}$ & R5 & $N / A$ & R5 & R5 & $\mathrm{X} 4$ & $\mathrm{X} 4$ & 14.4 & R5 & G2P 15\% & agree \\
\hline $\mathrm{F}$ & R5 & N/A & R5 & R5 & R5 & $\mathrm{X} 4$ & 17.5 & R5 & G2P 20\% & agree \\
\hline $\mathrm{F}$ & $\mathrm{D} / \mathrm{M}$ & $\mathrm{N} / \mathrm{A}$ & $\mathrm{X} 4$ & $\mathrm{X} 4$ & $\mathrm{X} 4$ & $\mathrm{X} 4$ & 1.7 & R5 & agree & PSSM \\
\hline $\mathrm{AE}$ & R5 & R5 & R5 & $\mathrm{X} 4$ & $\mathrm{X} 4$ & $\mathrm{X} 4$ & 5.3 & R5 & G2P 10\% & agree \\
\hline $\mathrm{AE}$ & R5 & $N / A$ & R5 & $\mathrm{X} 4$ & $\mathrm{X} 4$ & $\mathrm{X} 4$ & 7.9 & $\mathrm{D} / \mathrm{M}$ & G2P 10\% & PSSM \\
\hline $\mathrm{AE}$ & R5 & N/A & $\mathrm{X} 4$ & $\mathrm{X} 4$ & $\mathrm{X} 4$ & $\mathrm{X} 4$ & 1.8 & $\mathrm{X} 4$ & G2P 5\% & PSSM \\
\hline $\mathrm{AE}$ & R5 & $\mathrm{N} / \mathrm{A}$ & $\mathrm{X} 4$ & $\mathrm{X} 4$ & X4 & $\mathrm{X} 4$ & 2.7 & $\mathrm{D} / \mathrm{M}$ & G2P 5\% & PSSM \\
\hline$A E$ & R5 & $\mathrm{D} / \mathrm{M}$ & $\mathrm{X} 4$ & $\mathrm{X} 4$ & $\mathrm{X} 4$ & $\mathrm{X} 4$ & 1.8 & $\mathrm{X} 4$ & G2P 5\% & PSSM \\
\hline $\mathrm{AE}$ & $\mathrm{D} / \mathrm{M}$ & $\mathrm{N} / \mathrm{A}$ & $\mathrm{X} 4$ & $\mathrm{X} 4$ & $\mathrm{X} 4$ & $\mathrm{X} 4$ & 1.7 & $\mathrm{X} 4$ & agree & PSSM partial \\
\hline$A E$ & R5 & N/A & R5 & $\mathrm{X} 4$ & $\mathrm{X} 4$ & $\mathrm{X} 4$ & 9.6 & R5 & G2P 10\% & agree \\
\hline
\end{tabular}


Table 3. Cont.

\begin{tabular}{|c|c|c|c|c|c|c|c|c|c|c|}
\hline \multirow{2}{*}{ HIV-1 subtype } & \multirow{2}{*}{ RVA result } & \multirow[t]{2}{*}{$\begin{array}{l}\text { Trofile } \\
\text { result }\end{array}$} & \multicolumn{5}{|l|}{ G2P } & \multirow[t]{2}{*}{ webPSSM } & \multicolumn{2}{|l|}{ Discordance } \\
\hline & & & $5 \%$ cutoff & $10 \%$ cutoff & f 15\%cutoff & $20 \%$ cutoff & FPR & & G2P & PSSM \\
\hline $\mathrm{AE}$ & R5 & $\mathrm{N} / \mathrm{A}$ & R5 & $\mathrm{X} 4$ & $\mathrm{X} 4$ & $\mathrm{X} 4$ & 5.7 & R5 & G2P 10\% & agree \\
\hline $\mathrm{AE}$ & R5 & $N / A$ & R5 & $\mathrm{X} 4$ & $\mathrm{X} 4$ & $\mathrm{X} 4$ & 5.7 & R5 & G2P 10\% & agree \\
\hline $\mathrm{AE}$ & $\mathrm{D} / \mathrm{M}$ & $N / A$ & R5 & $\mathrm{X} 4$ & $\mathrm{X} 4$ & $\mathrm{X} 4$ & 8.7 & $\mathrm{D} / \mathrm{M}$ & G2P 10\% & agree \\
\hline $\mathrm{AE}$ & R5 & $\mathrm{N} / \mathrm{A}$ & R5 & $\mathrm{X} 4$ & $\mathrm{X} 4$ & $\mathrm{X} 4$ & 5 & $\mathrm{D} / \mathrm{M}$ & G2P 10\% & PSSM \\
\hline $\mathrm{AE}$ & R5 & $\mathrm{N} / \mathrm{A}$ & R5 & R5 & $\mathrm{X} 4$ & $\mathrm{X} 4$ & 10.5 & R5 & G2P 15\% & agree \\
\hline $\mathrm{AE}$ & R5 & $N / A$ & R5 & R5 & $\mathrm{X} 4$ & $\mathrm{X} 4$ & 10.5 & R5 & G2P 15\% & agree \\
\hline $\mathrm{AE}$ & R5 & $N / A$ & R5 & R5 & $\mathrm{X} 4$ & $\mathrm{X} 4$ & 12 & R5 & G2P 15\% & agree \\
\hline $\mathrm{AE}$ & R5 & $\mathrm{N} / \mathrm{A}$ & $\mathrm{X} 4$ & $\mathrm{X} 4$ & $\mathrm{X} 4$ & $\mathrm{X} 4$ & 4.1 & $\mathrm{D} / \mathrm{M}$ & G2P 5\% & PSSM \\
\hline $\mathrm{AE}$ & $\mathrm{D} / \mathrm{M}$ & N/A & R5 & R5 & R5 & R5 & 77.2 & R5 & G2P 5\% & PSSM \\
\hline $\mathrm{AE}$ & R5 & $\mathrm{N} / \mathrm{A}$ & $\mathrm{X} 4$ & $\mathrm{X} 4$ & $\mathrm{X} 4$ & $\mathrm{X} 4$ & 4.7 & $\mathrm{X} 4$ & G2P 5\% & PSSM \\
\hline $\mathrm{AE}$ & $\mathrm{D} / \mathrm{M}$ & N/A & R5 & R5 & $\mathrm{X} 4$ & $\mathrm{X} 4$ & 10.5 & R5 & G2P 5-10\% & PSSM \\
\hline $\mathrm{AE}$ & $\mathrm{D} / \mathrm{M}$ & $\mathrm{N} / \mathrm{A}$ & $\mathrm{X} 4$ & $\mathrm{X} 4$ & $\mathrm{X} 4$ & $\mathrm{X} 4$ & 1.7 & $\mathrm{X} 4$ & agree & PSSM partial \\
\hline AG & R5 & R5 & R5 & $\mathrm{X} 4$ & $\mathrm{X} 4$ & $\mathrm{X} 4$ & 6.4 & R5 & G2P 10\% & agree \\
\hline AG & R5 & R5 & R5 & $\mathrm{X} 4$ & $\mathrm{X} 4$ & $\mathrm{X} 4$ & 9.6 & R5 & G2P $10 \%$ & agree \\
\hline AG & R5 & $\mathrm{N} / \mathrm{A}$ & R5 & R5 & $\mathrm{X} 4$ & $\mathrm{X} 4$ & 13.8 & R5 & G2P 15\% & agree \\
\hline AG & R5 & R5 & R5 & R5 & $\mathrm{X} 4$ & $\mathrm{X} 4$ & 10.2 & R5 & G2P 15\% & agree \\
\hline AG & R5 & R5 & $\mathrm{X} 4$ & X4 & $\mathrm{X} 4$ & X4 & 4.8 & R5 & G2P 5\% & agree \\
\hline AG & R5 & $\mathrm{N} / \mathrm{A}$ & $\mathrm{X} 4$ & $\mathrm{X} 4$ & $\mathrm{X} 4$ & $\mathrm{X} 4$ & 2.6 & R5 & G2P 5\% & agree \\
\hline AG & R5 & N/A & R5 & $\mathrm{X} 4$ & $\mathrm{X} 4$ & $\mathrm{X} 4$ & 6.8 & R5 & G2P 10\% & agree \\
\hline AG & $\mathrm{D} / \mathrm{M}$ & R5 & R5 & R5 & R5 & R5 & 40.7 & R5 & G2P 5\% & PSSM \\
\hline AG & $\mathrm{D} / \mathrm{M}$ & $\mathrm{N} / \mathrm{A}$ & R5 & $\mathrm{X} 4$ & $\mathrm{X} 4$ & $\mathrm{X} 4$ & 5.8 & R5 & G2P 5\% & PSSM \\
\hline AG/G & R5 & R5 & R5 & R5 & $\mathrm{X} 4$ & $\mathrm{X} 4$ & 10.1 & R5 & G2P 15\% & agree \\
\hline AG & $\mathrm{D} / \mathrm{M}$ & N/A & $\mathrm{X} 4$ & $\mathrm{X} 4$ & $\mathrm{X} 4$ & $\mathrm{X} 4$ & 1.7 & R5 & agree & PSSM \\
\hline AG & $\mathrm{D} / \mathrm{M}$ & $\mathrm{N} / \mathrm{A}$ & $\mathrm{X} 4$ & $\mathrm{X} 4$ & $\mathrm{X} 4$ & $\mathrm{X} 4$ & 0.5 & $\mathrm{X} 4$ & agree & PSSM partial \\
\hline AG & R5 & $\mathrm{N} / \mathrm{A}$ & R5 & R5 & R5 & R5 & 39.6 & $\mathrm{D} / \mathrm{M}$ & agree & PSSM \\
\hline AG & $\mathrm{D} / \mathrm{M}$ & $\mathrm{N} / \mathrm{A}$ & $\mathrm{X} 4$ & $\mathrm{X} 4$ & $\mathrm{X} 4$ & $\mathrm{X} 4$ & 5.3 & R5 & agree & PSSM \\
\hline
\end{tabular}

G2P: Geno2Pheno; FPR: False Positive Rate; D/M: dual mixed N/A = sample was not analyzed; PSSM 'partial' refers to samples for which webPSSM agrees with the phenotypic result for the detection of $\mathrm{X} 4$ variants, but not on the presence or absence of CCR5-using variants.

doi:10.1371/journal.pone.0060566.t003

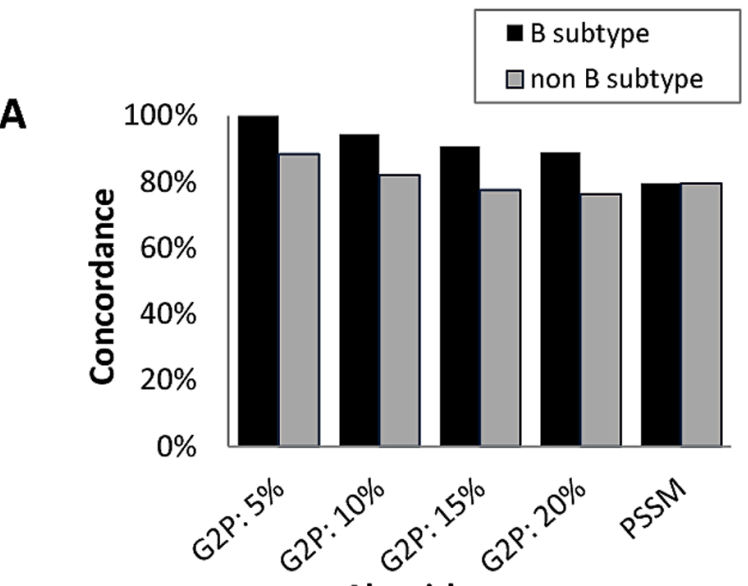

Algorithms

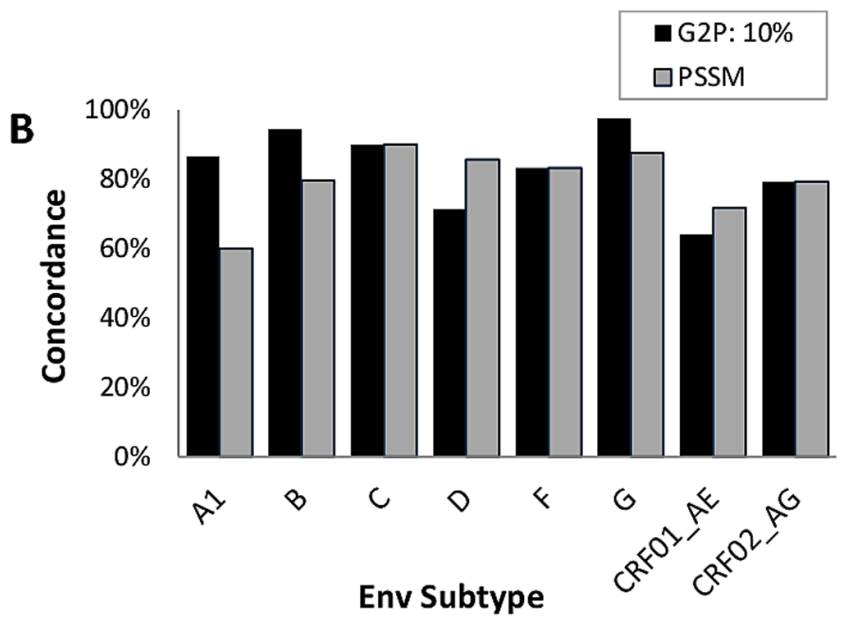

Figure 4. Concordance between tropism measured phenotypically and inferred genotypically using the Geno2pheno (coreceptor) and webPSSM algorithms. (A) Concordance for subtype B (black bars) and non-B subtype (grey bars) strains with Geno2Pheno (G2P) at different FPR

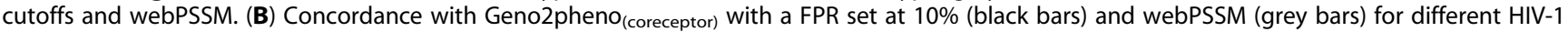
subtypes. The webPSSM X4/R5 matrix was used for all subtypes, except for subtype C, for which the subtype C SI/NSI matrix was used. doi:10.1371/journal.pone.0060566.g004 
subtype A1, CXCR4 usage was overestimated in all cases (6/6 discordant cases) (Table 3).

Overall, both Geno2Pheno ${ }_{[\text {coreceptor] }}$ and webPSSM overestimate the presence of $\mathrm{X} 4$ viruses for CRF01_AE. A similar trend was also observed for Geno2Pheno ${ }_{\text {[coreceptor] }}$ in the case of CRF02_AG and for webPSSM in the case of subtype A1, while webPSSM underestimates the presence of $\mathrm{X} 4$ for subtype $\mathrm{B}$. Taken together, these results point to an inadequacy of the genotypic prediction algorithms in correctly inferring tropism for some subtypes CRF01_AE and CRF02_AG, and for subtype Al in the case of webPSSM.

\section{Discussion}

In this study, the performance of an in-house Env-recombinant viral assay for determining viral tropism was evaluated in comparison to genotypic prediction using 2 widely used algo-

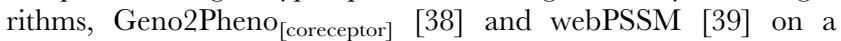
majority of non-B subtypes. Overall, we found good concordance between our phenotypic assay and these algorithms, as reflected by $85.2 \%$ concordance of the phenotype with Geno2Pheno [coreceptor] and $79.5 \%$ with webPSSM and relative kappa values of 0.6252 and 0.4544 respectively. The highest genotypic/phenotypic concordance was generally found for subtypes G, B and C strains, whereas, despite improved rules, substantial discordances involved non-B subtypes and CRFs. This is in line with previous studies reporting the performance of genotypic tools, mainly webPSSM (X4/R5 and SINSI matrices), Wetcat, Geno2Pheno ${ }_{\text {[coreceptor] }}$ or the $11 / 25$ rule, compared to the Phenoscript test or to the Trofile phenotypic assay [53,58,59] measuring the sensitivity and specificity of these algorithms to detect the presence of $\mathrm{X} 4$ strains. In order to compare our findings with previous reports which evaluated the reliability of different genotypic prediction tools for detecting X4 strains, sensitivity and specificity of these algorithms with respect to the recombinant viral assay were calculated, although this approach presents the intrinsic drawback of setting the phenotypic assay as the standard. We found overall good sensitivities with Geno2Pheno and webPSSM, similar to previous reports on the sensitivity and specificity ranges of different bioinformatics tools for subtype B and some non-B strains [5358]. Of note however, despite similar conclusions, concordance of different genotypic prediction tools with phenotypic assays did not always agree on which algorithm performed best, probably reflecting differences in the panel of viruses and of subtypes included, primer selection, and subsequent comparison with different phenotypic assays targeting the full Env or just the V1V3 portion. Although the purpose of this study was not to compare the performance of different bioinformatics tools for detecting X4 minority variants but rather to validate our in-house RVA, our findings confirm the high reliability of genotypic prediction tools for detecting the tropism of subtype B strains [53,54,56], but also highlight incongruent results for many non-B strains. This has been addressed by webPSSM by developing a specific matrix for subtype C. Concordance of webPSSM with phenotypic results increased from $75 \%$ using the webPSSM X4/R5 matrix (based on subtype B) (data not shown) to $90 \%$ using the webPSSM subtype C matrix; likewise Cohen kappa values shifted from negative (data not shown) to $>0.6$ using both algorithms respectively. Therefore, it is important to consider subtype when assessing the presence of $\mathrm{X} 4$ strains in the clinical context prior to maraviroc prescription. Our findings strongly argue in favor of using multiple genotypic prediction tools and to consider maintaining phenotypic testing for those subtypes for which coreceptor usage determination using genotypic tests features low concordance with phenotypic mea- sures, and for which prediction algorithms have not been tuned specifically, i.e. non-B, and non-C subtypes.

In this study, genotypic prediction featured the highest discordance with CRF01_AE and CRF02_AG and subtype A1. Of note, Geno2Pheno ${ }_{[\text {coreceptor] }}$ and webPSSM did not always predict the same tropism, as previously reported [60]. Geno2Pheno ${ }_{\text {[coreceptor] }}$ tended to overestimate the presence of CXCR4 usage (Table 3), while WebPSSM overestimated CXCR4-usage for subtype A1, but not for subtype B or CRF01_AE and CRF02_AG (Table 3). It may be important to keep in mind that when mixtures are present in the V3-loop, all possible combinations are genotyped, and the algorithm provides a tropism prediction for each possible clone. In this scenario, webPSSM would infer tropism for sequences that do not exist in the viral population, eventually leading to an overestimation of dual tropic variants, whereas the phenotypic assays only measures existing strains. Although this phenomenon does not account for mistakenly assigned coreceptor usage, (e.g. strict X4 rather than strict R5), it could explain the improved kappa values recorded for some subtypes when the reliability in detecting the presence of CXCR4using variants is compared. Such an improvement was particularly marked for subtypes B, G and CRF02_AG (Table 2).

Poor specificity has previously been reported for tropism prediction of subtype D strains by Geno2Pheno ${ }_{\text {[coreceptor] }}$ [46] and for CRF02_AG [19,45], for which specific determinants have been described to improve the algorithm. We therefore subjected our samples to the rules provided by Raymond [45] and those proposed shortly after by Esbjörnsson [19] for CRF02_AG: the Raymond rules, which combine the 11/25 rule and the net charge rule $(\mathrm{R} / \mathrm{K}$ at position 11 and/or $\mathrm{K}$ at position 25, or $\mathrm{R}$ at position $25+$ net charge $\geq+5$ or the net charge $\geq+6)[45,61]$ resulted in 7 discordant cases $(20.7 \%$ ) (3 R5 samples scored as X4 and 3 X4 samples scored as R5) and the Esbjörnsson rule (net charge $\geq+5$ and total charged $\mathrm{AA} \geq 8)$ [19] in 10 discordances (34.5\%) (4 missed $\mathrm{X} 4$ calls and $6 \mathrm{X} 4$ calls for $\mathrm{R} 5$ viruses). Therefore, the Raymond rules slightly improved concordance of genotypic prediction with phenotypic measure for CRF02_AG compared to Geno2Pheno ${ }_{\text {[coreceptor] }}$ and webPSSM while the Esbjornsson rules further increased false positive $\mathrm{X} 4$ calls on our samples. While this manuscript was under revision, Raymond et al. reported similarly low sensitivity and specificity of Geno2Pheno ${ }_{[-}$ coreceptor] (10\% FPR cutoff) for CRF01_AE, and proposed a new rule combining the $11 / 25$ rule and disruption of the potential $\mathrm{N}$ glycosylation site PNG $\left(\mathrm{N}_{6} \mathrm{NT}_{8}\right)$ within the V3-loop [62]. Using a similar approach, we found that in our samples, the presence of a positively charged AA (K or R) at positions 11 or 25 was relatively rare $(R / K$ at position 11 in $6 / 40$ sequences and $K$ at position 25 in one sequence), but reliably translated into CXCR4 usage measured phenotypically. Position 11 hosted a $\mathrm{S}$ in 30/40 sequences and a $\mathrm{G}$ in $3 / 40$ sequences; position 25 displayed a negatively charged AA (D or E) in 35 sequences. The total number of positively charged $\mathrm{AA}$, total net charge, or total charge, which was generally high $(>+5)$, did not provide further support for sorting CXCR4-using strains in our samples, in agreement with the findings reported by Raymond et al. [62]. In 6/8 phenotypically $\mathrm{X} 4$ strains in which positions 11 and 25 were not positively charged, the PNG $\left(\mathrm{N}_{6} \mathrm{NT}_{8}\right)$ was (or was likely to be, due to mixtures) disrupted and the net charge was $\geq+4$, as reported by Raymond et al. [62]. The Raymond rules improved concordance of the phenotypic test with genotypic prediction from $61.4 \%$ with Geno2Pheno $_{\text {[coreceptor] }}$ and $71.8 \%$ with webPSSM to $87.2 \%$ (34/ 39) for this CRF. Nonetheless, with these rules $(11 \mathrm{~K} / \mathrm{R}$ and/or $25 \mathrm{~K}$ or disrupted $\mathrm{PNG}+$ net charge $\geq+4$ [62]) in 2/25 cases, phenotypically R5 samples were scored as X4 and 2/14 
phenotypically $\mathrm{X} 4$ samples were predicted to be R5, suggesting that other criteria apply to this CRF and larger scale studies combining phenotypic testing to genotypic tuning combining the $11 / 25$ rule to the PNG and to charge will be needed to further improve sensitivity and specificity of prediction tools. We cannot exclude that in our study, the use of bulk sequences may impact the reliability of prediction rules, whereas the rules by Raymond were partially based on clonal samples, where the relative weight of each position is absolute rather than being relative to its proportion within the quasispecies.

Three technical reasons could account for discordant results between genotypic prediction and phenotypically determined tropism: PCR selection, a bias/selection arising from the recombination step of the RVA, inadequately inferred tropism by genotypic tools, consequent to subtype-related specificities not taken into account by the algorithm, either within the V3 loop or in other regions of Env. To minimize a potential impact of PCR selection, 5 independent PCR reactions were pooled and the same amplicon used to produce recombinant viruses was sequenced. Nonetheless, whereas comparison of the Env-RVA and genotypic prediction by Geno2Pheno and webPSSM were based on the use of the same PCR pool, the Trofile ESTA was performed using an independent plasma tube and different PGR primers, eventually translating into PCR selection. Hence, it is not possible to exclude that failure to pick-up X4 minority variants by the RVA (1 CRF01_AE) or by the Trofile ESTA (1 CRF02_AG), reflect PCR selection, particularly in the case of poorly infectious recombinant or pseudotyped particles. Selection during the recombination step was ruled out as the V3-loop sequences from viral supernatants (after the recombination step) were identical to the parental PCR amplicon that served to produce recombinant viruses. When assessed, tropism of CRF01_AE and CRF02_AG strains assessed using the Trofile ESTA matched the phenotype determined by the RVA and disagreed with the Geno2Pheno ${ }_{[\text {coreceptor] }}$ prediction in all but two cases (Table 3). The Trofile ESTA was chosen among all available tropism phenotypic tests because it is a high sensitivity and specificity single cycle pseudovirus assay [30]. Lastly, repeat experiments in the presence of CCR5 and CXCR4 inhibitors confirmed the phenotypic results, strongly indicating that the Geno2Pheno $_{[\text {coreceptor] }}$ and webPSSM algorithms require more specific improvements for some subtypes, particularly CRF01_AE and CRF02_AG, and that the RVA described here reliably indicates coreceptor usage. It is known that the V3-loop is not the sole Env determinant of HIV-1 co-receptor usage. Sequence changes within the V1, V2 and C4 regions of gp120 [13,63-67], as well as the level of glycosylation [68-70] can also profoundly impact coreceptor usage. In this study, it is not possible to rule out that some discordant results arise from the comparison of coreceptor usage predictions based on the V3-loop sequence only to a phenotypic assay taking into account the whole Env ectodomain.

Various commercial and non-commercial phenotypic assays have been developed over the last 10 years to measure tropism. These are based on different approaches to produce recombinant viruses, including homologous recombination, pseudotyping, or a combination of both; they target different parts of Env, ranging

\section{References}

1. Dalgleish AG (1984) The CD4 (T4) antigen is an essential component of the receptor for the AIDS retrovirus. Nature 312: 763-767.

2. Deng H, Liu R, Ellmeier W, Choe S, Unutmaz D, et al. (1996) Identification of a major co-receptor for primary isolates of HIV-1. Nature 381: 661-666.

3. Oberlin E (1996) The CXC chemokine SDF-1 is the ligand for LESTR/fusin and prevents infection by T-cell-line adapted HIV-1. Nature 382: 833-835. from the V1-V3 region only (e.g. Phenoscript [34], PhenXR [71]) to the full Env (e.g. ESTA [30]); the producer and the target cells, as well as the readout (virally-encoded luciferase or GFP reporter gene (e.g. ESTA [30], TTT [35], the Virco Assay [32], two noncommercial assays utilizing recombinant particles and pseudovirions respectively [33,72], and the RVA presented here), or target cell line containing a LTR- $\beta$-Galactosidase reporter which is activated upon infection (e.g. Phenoscript [34], PhenXR [71]) further distinguish these tests. These are recorded in Table 1. The RVA presented here mostly resembles the TTT assay in the design of the backbone, production of recombinant viral particles through homologous recombination and location of Luciferase reporter in the place of Nef [35]. The TTT showed high performance in terms of Env amplification and production of recombinant viruses, particularly for subtypes that were difficult to amplify using our primers (D and F), likely due to primer location. The TTT group also selected one U87-CD4.CXCR4 cell clone with high expression of CXCR4 to increase the limit of detection of $\mathrm{X} 4$ minority variants [35]. In our design, we verified the expression of CXCR 4 and only maintained cells in culture for a limited number of passages. To ensure the lower limit of detection of X4 strains was maintained, we tested the performance of the RVA using serial dilutions and systematically discarded experiments where the lower threshold of infection of U87.CD4.CXCR4 cells by NL4-3 did not reach 100,000 RLU (Fig. 2). It would be interesting to compare the performance of different phenotypic assays using a large panel of samples, although this could not be performed here because of insufficient plasma from the sample to allow independent testing and repeat experiments in different laboratories.

Taken together, the findings reported here strongly support the need for further large-scale studies to improve prediction models and/or to appeal to more than one algorithm when non-B subtypes are involved. The use of phenotypic measurements could nevertheless be required in cases where different algorithms point to potential difficulties in inferring the correct tropism. Such a confirmation is important in the clinical set-up as a false prediction of X4 variants may lead to exclusion of patients who could have benefited from prescription of CGR5 inhibitors while false prediction of R5 only variants may lead to selection and reemergence of X4-strains under maraviroc pressure (Baatz et al., 2011; Kuhmann and Hartley, 2008; Pugach et al., 2007; Westby et al., 2007).

\section{Acknowledgments}

The authors are deeply grateful to Christos Petropoulos and Laura Napolitano for enriching discussions and critical reading of the manuscript, and to Olivier Collignon for support with statistical analyses.

\section{Author Contributions}

Conceived and designed the experiments: MM DPB. Performed the experiments: MM ML JYS AR YL. Analyzed the data: MM DS JYS YL ESS DPB. Contributed reagents/materials/analysis tools: CV CSD JCS. Wrote the paper: MM DPB. Critically read and helped improve the manuscript: CV YL ESS CSD.
4. Feng Y, Broder CC, Kennedy PE, Berger EA (1996) HIV-1 entry cofactor : functional cDNA cloning of a seven-transmembrane $G$ protein-coupled receptor. Science 272: $872-877$.

5. Choe H (1996) The [beta]-chemokine receptors CCR3 and CCR5 facilitate infection by primary HIV-1 isolates. Cell 85: 1135-1148.

6. Dragic T (1996) HIV-1 entry into CD4+ cells is mediated by the chemokine receptor CC-CKR-5. Nature 381: 667-673. 
7. Alkhatib G, Combadiere C, Broder C, Feng Y, Kennedy P, et al. (1996) CC CKR5: a RANTES, MIP-1alpha, MIP-1beta receptor as a fusion cofactor for macrophage-tropic HIV-1. Science 272: 1955-1958.

8. Weissenhorn W, Dessen A, Harrison S, Skehel J, Wiley D (1997) Atomic structure of the ectodomain from HIV-1 gp41. Nature 387: 426-430.

9. Cardozo T (2007) Structural basis of co-receptor selectivity by the HIV-1 V3 loop. AIDS Res Hum Retroviruses 23: 415-426.

10. Shioda T, Levy JA, Cheng-Mayer C (1992) Small amino acid changes in the V3 hypervariable region of gp 120 can affect the T-cell-line and macrophage tropism of human immunodeficiency virus type 1. Proc Natl Acad Sci USA 89: 9434 9438.

11. Berger E, Doms R, Fenyo E, Korber B, Littman D, et al. (1998) A newclassification for HIV-1. Nature 391: 240.

12. Hartley O, Klasse PJ, Sattentau QJ, Moore JP (2005) V3: HIV's Switch-Hitter. AIDS Research and Human Retroviruses 21: 171-189.

13. Pastore C, Nedellec R, Ramos A, Pontow S, Ratner L, et al. (2006) Human immunodeficiency virus type 1 coreceptor switching: V1/V2 gain-of-fitness mutations compensate for V3 loss-of-fitness mutations. J Virol 80: 750-758.

14. Chalmet K, Dauwe K, Foquet L, Baatz F, Seguin-Devaux C, et al. (2011) Presence of CXCR4-Using HIV-1 in Patients With Recently Diagnosed Infection: Correlates and Evidence for Transmission. Journal of Infectious Diseases.

15. Schuitemaker H, van 't Wout A, Lusso P (2011) Clinical significance of HIV-1 coreceptor usage. Journal of Translational Medicine 9: 1-17.

16. Bratt G, Karlsson A, Leandersson AC, Albert J, Wahren B, et al. (1998) Treatment history and baseline viral load, but not viral tropism or CCR-5 genotype, influence prolonged antiviral efficacy of highly active antiretroviral treatment. AIDS 12: 2193-2202.

17. Bjorndal A, Deng H, Jansson M, Fiore J, Colognesi C, et al. (1997) Coreceptor usage of primary human immunodeficiency virus type 1 isolates varies according to biological phenotype. J Virol 71: 7478-7487.

18. Connor RI, Sheridan KE, Ceradini D, Choe S, Landau NR (1997) Change in coreceptor use correlates with disease progression in HIV-1 infected individuals. J Exp Med 185: 621-628.

19. Esbjornsson J, Mansson F, Martinez-Arias W, Vincic E, Biague A, et al. (2010) Frequent CXCR4 tropism of HIV-1 subtype A and CRF02_AG during latestage disease - indication of an evolving epidemic in West Africa. Retrovirology 7: 23 .

20. Fenyö EM, Esbjörnsson J, Medstrand P, Jansson M (2011) Human immunodeficiency virus type 1 biological variation and coreceptor use: from concept to clinical significance. Journal of Internal Medicine 270: 520-531.

21. Blaak H (2000) In vivo HIV-1 infection of CD45RA+CD4+ T cells is established primarily by syncytium-inducing variants and correlates with the rate of CD4+ T cell decline. Proc Natl Acad Sci USA 97: 1269-1274.

22. Fatkenheuer G, Nelson M, Lazzarin A, Konourina I, Hoepelman A, et al. (2008) Subgroup analyses of maraviroc in previously treated R5 HIV-1 infection. N Engl J Med 359: 1442-1455.

23. Gulick R, LalezariJ, Goodrich J, Clumeck N, DeJesus E, et al. (2008) Maraviroc for previously treated patients with R5 HIV-1 infection. N Engl J Med 359: 1429-1441.

24. Harrigan PR, Geretti AM (2011) Genotypic tropism testing: evidence-based or leap of faith. AIDS 25: 257-264.

25. Kuhmann SE, Hartley O (2008) Targeting chemokine receptors in HIV: A status report. Annual Review of Pharmacology and Toxicology. 425-461.

26. Westby M, Smith-Burchnell C, Mori J, Lewis M, Mosley M, et al. (2007) Reduced maximal inhibition in phenotypic susceptibility assays indicates that viral strains resistant to the CCR 5 antagonist maraviroc utilize inhibitor-bound receptor for entry. J Virol 81: 2359-2371.

27. Baatz F, Nijhuis M, Lemaire M, Riedijk M, Wensing AMJ, et al. (2011) Impact of the HIV-1 Genetic Context outside HR1/HR2 on Resistance to the Fusion Inhibitor Enfuvirtide and Viral Infectivity in Clinical Isolates. PLoS ONE 6: e21535.

28. Pugach P, Marozsan AJ, Ketas TJ, Landes EL, Moore JP, et al. (2007) HIV-1 clones resistant to a small molecule CCR5 inhibitor use the inhibitor-bound form of CCR5 for entry. Virology 361: 212-228.

29. Rose JD, Rhea AM, Weber J, Quinones-Mateu ME (2009) Current tests to evaluate HIV-1 coreceptor tropism. Current Opinion in HIV \& AIDS 4: 136142.

30. Reeves JD, Coakley E, Petropoulos CJ, Whitcomb JM (2009) An EnhancedSensitivity Trofile ${ }^{\text {TM }}$ HIV Coreceptor Tropism Assay for Selecting Patients for Therapy with Entry Inhibitors Targeting CCR5: A Review of Analytical and Clinical Studies. The Journal of Viral Entry 3: 94-102.

31. Whitcomb JM, Huang W, Fransen S, Limoli K, Toma J, et al. (2007) Development and characterization of a novel single-cycle recombinant-virus assay to determine human immunodeficiency virus type 1 coreceptor tropism. Antimicrob Agents Chemother 51: 566-575.

32. Van Baelen K, Vandenbroucke I, Rondelez E, Van Eygen V, Vermeiren H, et al. (2007) HIV-1 coreceptor usage determination in clinical isolates using clonal and population-based genotypic and phenotypic assays. J Virol Methods 146: $61-73$.

33. Lin NH, Negusse DM, Beroukhim R, Giguel F, Lockman S, et al. (2010) The design and validation of a novel phenotypic assay to determine HIV-1 coreceptor usage of clinical isolates. Journal of Virological Methods 169: 39-46.
34. Trouplin V, Salvatori F, Cappello F, Obry V, Brelot A, et al. (2001) Determination of coreceptor usage of human immunodeficiency virus type 1 from patient plasma samples by using a recombinant phenotypic assay. J Virol 75: 251-259.

35. Raymond S, Delobel P, Mavigner M, Cazabat M, Souyris C, et al. (2010) Development and performance of a new recombinant virus phenotypic entry assay to determine HIV-1 coreceptor usage. Journal of Clinical Virology 47: $126-130$.

36. Asboe D, Aitken C, Boffito M, Booth C, Cane P, et al. (2012) British HIV Association guidelines for the routine investigation and monitoring of adult HIV1-infected individuals 2011. HIV Medicine 13: 1-44.

37. Delobel P, Nugeyre M-T, Cazabat M, Pasquier C, Marchou B, et al. (2007) Population-Based Sequencing of the V3 Region of env for Predicting the Coreceptor Usage of Human Immunodeficiency Virus Type 1 Quasispecies. Journal of Clinical Microbiology 45: 1572-1580.

38. Beerenwinkel N, Däumer M, Oette M, Korn K, Hoffmann D, et al. (2003) Geno2pheno: estimating phenotypic drug resistance from HIV-1 genotypes. Nucleic Acids Research 31: 3850-3855.

39. Jensen M, Li F, van 't Wout A, Nickle D, Shriner D, et al. (2003) Improved coreceptor usage prediction and genotypic monitoring of R5-to-X4 transition by motif analysis of human immunodeficiency virus type 1 env V3 loopsequences. J Virol 77: 13376-13388.

40. Vandekerckhove LPR, Wensing AMJ, Kaiser R, Brun-Vézinet F, Clotet B, et al. (2011) European guidelines on the clinical management of HIV-1 tropism testing. The Lancet Infectious Diseases 11: $394-407$.

41. McGovern RA, Harrigan PR, Swenson LC (2010) Genotypic Inference of HIV1 Tropism Using Population-based Sequencing of V3. J Vis Exp: e2531.

42. Recordon-Pinson P, Soulie C, Flandre P (2010) Evaluation of the genotypic prediction of HIV-1 coreceptor use versus a phenotypic assay and correlation with the virological response to maraviroc: the ANRS GenoTropism study. Antimicrob Agents Chemother 54: 3335-3340.

43. Swenson LC, Moores A, Low AJ, Thielen A, Dong W, et al. (2010) Improved detection of CXCR4-using HIV by V3 genotyping: application of populationbased and "deep" sequencing to plasma RNA and proviral DNA. J Acquir Immune Defic Syndr 54: 506-510.

44. Garrido C, Roulet V, Chueca N, Poveda E, Aguilera A, et al. (2008) Evaluation of Eight Different Bioinformatics Tools To Predict Viral Tropism in Different Human Immunodeficiency Virus Type 1 Subtypes. Journal of Clinical Microbiology 46: 887-891.

45. Raymond S, Delobel P, Mavigner M, Cazabat M, Souyris C, et al. (2009) Genotypic Prediction of HIV-1 CRF02-AG Tropism. J Clin Microbiol 47: 2292-2294.

46. Raymond S, Delobel P, Chaix ML, Cazabat M, Encinas S, et al. (2011) Genotypic prediction of HIV-1 subtype D tropism. Retrovirology 8: 56.

47. de Oliveira T, Deforche K, Cassol S, Salminen M, Paraskevis D, et al. (2005) An automated genotyping system for analysis of HIV-1 and other microbial sequences. Bioinformatics 21: 3797-3800.

48. Van Laethem K, Schrooten Y, Lemey P, Wijngaerden EV, Wit SD, et al. (2005) A genotypic resistance assay for the detection of drug resistance in the human immunodeficiency virus type 1 envelope gene. Journal of Virological Methods 123: 25-34.

49. Verhofstede C, Brudney D, Reynaerts J, Vaira D, Fransen K, et al. (2011) Concordance between HIV-1 genotypic coreceptor tropism predictions based on plasma RNA and proviral DNA. HIV Medicine 12: 544-552.

50. Batra M, Tien PC, Shafer RW, Contag CH, Katzenstein DA (2000) HIV type 1 envelope subtype $\mathrm{C}$ sequences from recent seroconverters in Zimbabwe. AIDS Res Hum Retroviruses 16: 973-979.

51. Chakrabarti AK, Caruso L, Ding M, Shen C, Buchanan W, et al. (2009) Detection of HIV-1 RNA/DNA and CD4 mRNA in feces and urine from chronic HIV-1 infected subjects with and without anti-retroviral therapy. AIDS Res Ther 6: 20 .

52. O'Doherty U, Swiggard WJ, Malim MH (2000) Human Immunodeficiency Virus Type 1 Spinoculation Enhances Infection through Virus Binding. Journal of virology 74: 10074-10080

53. Chueca N, Garrido C, Álvarez M, Poveda E, de Dios Luna J, et al. (2009) Improvement in the determination of HIV-1 tropism using the $\mathrm{V} 3$ gene sequence and a combination of bioinformatic tools. Journal of Medical Virology 81: 763-767.

54. Seclén E, Garrido C, Gonzalez MdM, Gonzalez-Lahoz J, de Mendoza C, et al. (2010) High sensitivity of specific genotypic tools for detection of X4 variants in antiretroviral-experienced patients suitable to be treated with CCR5 antagonists. Journal of Antimicrobial Chemotherapy 65: 1486-1492.

55. Qu S, Ma L, Yuan L, Xu W, Hong K, et al. (2010) Co-receptor usage and prediction of V3 genotyping algorithms in HIV-1 subtype B' from paid blood donors experienced anti-retroviral therapy in Chinese central province. Virol J 7: 280.

56. Delgado E, Fernandez-Garcia A, Vega Y, Cuevas T, Pinilla M, et al. (2012) Evaluation of genotypic tropism prediction tests compared with in vitro coreceptor usage in HIV-1 primary isolates of diverse subtypes. Journal of Antimicrobial Chemotherapy 67: 25-31.

57. Poveda E, Seclen E, Gonzalez Mdel M, Garcia F, Chueca N, et al. (2009) Design and validation of new genotypic tools for easy and reliable estimation of HIV tropism before using CCR5 antagonists. J Antimicrob Chemother 63: 1006-1010. 
58. Poveda E, Briz V, Roulet V, del Mar Gonzalez M, Faudon J-L, et al. (2007) Correlation between a phenotypic assay and three bioinformatic tools for determining HIV co-receptor use. AIDS 21: 1487-1490 1410.1097/QAD.1480b1013e32826fb32741.

59. de Mendoza C, Van Baelen K, Poveda E, Rondelez E, Zahonero N, et al. (2008) Performance of a population-based HIV-1 tropism phenotypic assay and correlation with V3 genotypic prediction tools in recent HIV-1 seroconverters. J Acquir Immune Defic Syndr 48: 241-244.

60. Rodriguez JJ, Seclen E, Poveda E, Varela E, Regueiro B, et al. (2011) Variability in HIV viral tropism determination using different genotypic algorithms in patients infected with B versus non-B HIV-1 subtypes]. Enferm Infecc Microbiol Clin 29: 4-8.

61. Raymond S, Delobel P, Mavigner M, Cazabat M, Souyris C, et al. (2008) Correlation between genotypic predictions based on V3 sequences and phenotypic determination of HIV-1 tropism. AIDS 22: F11-F16.

62. Raymond S, Delobel P, Rogez S, Encinas S, Bruel P, et al. (2012) Genotypic Prediction of HIV-1 CRF01-AE Tropism. J Clin Microbiol 5: 5.

63. Hoffman NG, Seillier-Moiseiwitsch F, Ahn J, Walker JM, Swanstrom R (2002) Variability in the Human Immunodeficiency Virus Type 1 gp120 Env Protein Linked to Phenotype-Associated Changes in the V3 Loop. Journal of Virology 76: 3852-3864.

64. Huang CC (2005) Structure of a V3-containing HIV-1 gp120 core. Science 310: 1025-1028.

65. Nabatov AA, Pollakis G, Linnemann T, Kliphius A, Chalaby MIM, et al. (2004) Intrapatient Alterations in the Human Immunodeficiency Virus Type 1 gp120 V1V2 and V3 Regions Differentially Modulate Coreceptor Usage, Virus
Inhibition by CG/CXC Chemokines, Soluble CD4, and the b12 and $2 \mathrm{G} 12$ Monoclonal Antibodies. Journal of Virology 78: 524-530.

66. Zolla-Pazner S, Cardozo T (2010) Structure-function relationships of HIV-1 envelope sequence-variable regions refocus vaccine design. Nat Rev Immunol 10: $527-535$.

67. Ross TM, Cullen BR (1998) The ability of HIV type 1 to use CCR-3 as a coreceptor is controlled by envelope V1/V2 sequences acting in conjunction with a CCR-5 tropic V3 loop. Proc Natl Acad Sci U S A 95: 7682-7686.

68. Clevestig P, Maljkovic I, Casper C, Carlenor E, Lindgren S, et al. (2005) The X4 phenotype of HIV type 1 evolves from R 5 in two children of mothers, carrying $\mathrm{X} 4$, and is not linked to transmission. AIDS Res Hum Retroviruses 21: 371-378.

69. McCaffrey RA, Saunders C, Hensel M, Stamatatos L (2004) N-Linked Glycosylation of the V3 Loop and the Immunologically Silent Face of gp120 Protects Human Immunodeficiency Virus Type 1 SF162 from Neutralization by Anti-gp120 and Anti-gp41 Antibodies. Journal of Virology 78: 3279-3295.

70. Pollakis G, Kang S, Kliphuis A, Chalaby MIM, Goudsmit J, et al. (2001) NLinked Glycosylation of the HIV Type-1 gp120 Envelope Glycoprotein as a Major Determinant of CCR5 and CXCR4 Coreceptor Utilization. Journal of Biological Chemistry 276: 13433-13441.

71. Hamy F, Vidal V, Hubert S, Klimkait T (2007) Hybridization-based assay and replicative phenotyping as diagnostic platform for determination of coreceptor tropism. 5th European HIV drug resistance workshop: Abstract 60.

72. Gonzalez N, Perez-Olmeda M, Mateos E, Cascajero A, Alvarez A, et al. (2010) A sensitive phenotypic assay for the determination of human immunodeficiency virus type 1 tropism. J Antimicrob Chemother 65: 2493-2501. 